\title{
Technical Assistance to
}

Ohio Closure Sites

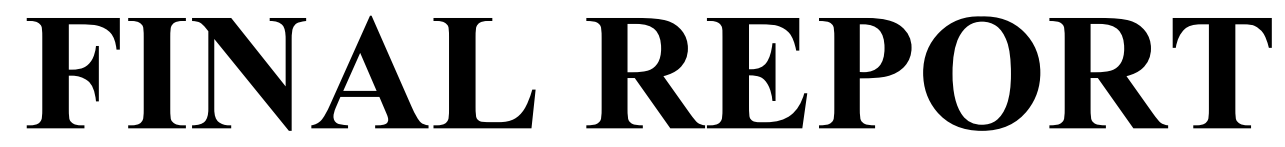

Recommendations to Address Contaminated Soils, Concrete, and Corrective Action Management Unit/Groundwater Contamination at Ashtabula, Ohio

Technical Assistance \#141

June 25-28, 2002 


\section{TABLE OF CONTENTS}

\section{Recommendations to Address Contaminated Soils, Concrete, and Corrective Action}

Management Unit/Groundwater Contamination at Ashtabula, Ohio

\section{EXECUTIVE SUMMARY}

$1.0 \quad$ SOILS

1.1 Background/Baseline

1.2 Critical Issues

1.3 Evaluation of Alternatives

1.4 Recommendations

1.4.1 Approach

1.4.2 Rationale

1.4.3 Technology Options

1.4.4 Unresolved Issues

1.4.5 Action Items

2.0 CONCRETE

2.1 Background/Baseline

2.2 Critical Issues

2.3 Recommendations

2.3.1 Option 1

2.3.2 Option 2

2.3.3 Option 3

$2.4 \quad$ Overall Recommendations

3.0 CAMU/GROUNDWATER

3.1 Background/Baseline

3.2 Critical Issues

3.3 Unresolved Issues

3.4 Baseline Technology

3.5 Evaluation of Alternatives

3.5.1 CAMU Source Remediation

3.5.2 Groundwater Plume Treatment

3.6 Recommendations

4.0 POTENTIAL FOR CONTINUED INVOLVEMENT

ATTACHMENT 1 - Technical Assistance Request

ATTACHMENT 2 - Contact Information for Technical Assistance Team 


\section{EXECUTIVE SUMMARY}

The Ashtabula Environmental Management Project (AEMP) at Department of EnergyOhio (DOE-OH) requested technical assistance from the EM-50 Lead Lab to aid in defining new cost and time effective approaches in the following problem areas: soils, concrete, and groundwater/Corrective Action Management Unit (CAMU) at RMIES in Ashtabula, Ohio. Attachment 1 provides the site request for assistance.

The technical assistance team assembled for this request is provided in Attachment 2. These individuals reviewed key site information prior to convening with DOE and contractor personnel (RMIES and Earthline) for a three-and-a-half-day meeting to better understand baseline technologies, limitations, and site-specific issues. After listening to presentations about the nature and extent of known contamination, the team broke out into several groups to brainstorm ideas and develop viable solutions.

This executive summary details unresolved issues requiring management attention as well as recommendations to address soils, concrete, and groundwater/CAMU. It also provides a summary of additional technical assistance that could be provided to the site. More details are presented in the body of this report.

\section{SOILS}

Unresolved Issues. Prior to implementing recommendations to address soils, the following issues will need to be resolved.

- An acceptable method will need to be established for demonstrating that:

- Compliance with cleanup requirements is met for soil segregated as clean.

- Buried contamination does not exist for areas where this might be of concern.

- Soils beneath pads abandoned in place meet site cleanup requirements, in the event that pads are left behind.

- The optimal suite of technologies will need to be identified, their performance characteristics documented for the site, and site-specific standard operating procedures (SOPs) developed.

- If sodium iodide (NaI) scanning technologies are used, trigger levels will need to be determined that can be used for reliably segregating clean soils from contaminated soils.

- Appropriate lift sizes will need to be determined.

- An excavation logic will need to be developed for the site that will govern how excavation work is conducted.

Recommendations. The approach selected by the technical assistance team focuses on integrating "real-time" data collection into the excavation process, and using resulting data to address the uncertainties inherent in the actual footprint of contamination. The team maintains that additional characterization prior to initiation of site remediation activities will not significantly impact remedial decision-making. Based on all available 
current information, areas should be identified that are known to require remediation. Excavation should be conducted sequentially with "lifts" or "layers" of soil removed. After excavating each lift, data collection would take place over the exposed dig face to determine the contamination footprint within that dig face. A variety of technologies, such as NaI and high purity germanium (HPGe) detectors, could be used to scan surface soils. In Situ HPGe Gamma Spectroscopy Measurement System, Mobile NaI Scanning Systems (large crystal) used at Fernald Environmental Management Project (Gator, RSS, RTRAK, EMS), and FIDLER-type systems combined with GPS/GIS are types of applications that might be appropriate. Work should proceed until all known or encountered contamination has been identified.

Contaminated soil identified by this excavation process would be segregated by whether they have exceeded the cleanup criteria based on real-time measurements. Clean soils could be used for backfill, assuming sufficient information was collected to satisfy closure requirements. To be successful, this approach would require data collection technologies with sufficiently low detection limits to support the segregation of soils at $30 \mathrm{pCi} / \mathrm{g}$ for total uranium (U), and an excavation logic that provides sufficient time for dig-face screening to take place without jeopardizing excavation efficiency. This approach allows focus on remedial efforts rather than additional characterization, provides an efficient means for addressing uncertainties present in the contamination footprints, minimizes the possibility that clean soils are inadvertently excavated for offsite disposal, and provides at least some of the information that would be required for reusing excavated clean soils as backfill. Moreover, from a management perspective, this approach saves costs by reducing the volume of soil that needs to be shipped off site and also saves time given that real-time instruments support excavation.

\section{CONCRETE}

Unresolved Issues. Prior to implementing recommendations to address concrete, the following issues will need to be resolved.

- Although not disallowed by the decommissioning plan, leaving uncontaminated buildings and underground concrete is not specifically addressed and written authority will need to be obtained. This may be as simple as a letter of correspondence between ODH and RMI.

- There is no current procedure to clear the footings for free release. However, we were told that there was precedence in the State of Ohio to verify footings clean and bury them in place.

- Under the current contract the ten buildings and the uncontaminated concrete are not allowed to be left in place and will have to be agreed upon through contract negotiations between DOE and RMI.

- If the local landfill is considered for disposal of clean concrete, the site will need to address opposition to placing any concrete into the landfill that was previously in a contaminated area even if it has been declared clean. 
Recommendations. The technical assistance team proposes three potential approaches for addressing concrete slabs and foundations. The three options are presented below:

- Option 1 - Remove and dispose of all concrete as low-level waste (including the ten buildings slated for being left on site).

- Option 2 - Decontaminate and segregate some of the high volume foundations (extrusion press, etc.) as clean, and treat all slabs as contaminated except for the slabs under the ten buildings RMI wants to leave in place. All contaminated concrete would be crushed and sent to a low-level radioactive waste site.

- Option 3 - Decontaminate as much concrete as is feasible and then segregate the concrete. The clean concrete would be left in place or crushed and disposed of at the local landfill or used as on site fill material. All contaminated concrete would be crushed and sent to a low-level radioactive waste (LLRW) site.

In order to narrow the options down to a preferred alternative, more cost information is needed. The amount of decontamination and handling prior to free-releasing any concrete is key to determine which of these options is most cost-effective for AEMP. In the short-term, it is recommended the Ashtabula site obtain detailed information on extent of contamination by first mapping existing surveys to determine where more surveying/sampling needs to be conducted. Also the locations where piping and underground utilities (that will have to be removed) go through the foundations should be mapped to show where footings would have to be removed. The site should take steps to optimize equipment used for characterization, decontamination and demolition by completing a technology matrix. Options for waste disposal should also be investigated and documented. To leave the ten buildings in place, protocols for releasing buildings must be developed, as there is a cost for the additional sampling and approvals. A protocol for leaving the concrete footings in place is also needed.

When these short-term actions are complete, an independent cost benefit evaluation and a timeline should be completed using this information. It is possible that although one option may be cheaper it may also add significantly to the decommissioning schedule, which may not be desirable. It is estimated that completing all the short-term actions and this cost benefit analysis and timeline may cost on the order of $\$ 50 \mathrm{~K}$. However, a savings on the order of $\$ 1$ million over the baseline may be possible.

\section{CAMU/GROUNDWATER}

Unresolved Issues. Prior to implementing recommendations for CAMU and groundwater, the following issues will need to be resolved.

- The site will need to determine whether trichloroethylene (TCE) needs to be treated prior to sending to Envirocare (soil is believed to be destined for Subtitle C landfill with/without TCE). If it needs to be treated, there is a need to consider treatment during staging after excavation.

- It is uncertain whether the barium in the shale wells is naturally occurring, associated with drilling muds or other well installation issues, or is process related. More 
information is also needed to understand the presence of lead in glacial till and at depth.

- The team also felt that there is significant uncertainty associated with the rates and completeness of bioreduction of TCE that will be stimulated by the hydrogen release compound (HRC) interim action that is currently in progress.

- Another issue that should be addressed is the willingness of ODH to accept risk-based assessments of impact of $U$ contaminated groundwater at the site on a long-term basis.

Recommendations. The recommendations for groundwater and the CAMU have been combined since characterization and remediation cannot realistically be separated in this area. First, the team recommends that direct-push technology be used to further characterize the site including the CAMU source area and plume to support the design and optimization of the remedial system. There is a need to simultaneously better define lithology, determine which wells can be abandoned and where new wells may be needed, enhance the conceptual site model, and design a monitoring strategy using multiple, realtime measurements (e.g. SCAPS Cone Penetrometer, beginning late fiscal year 2002). The team recommends that the site accelerate excavation (excavate CAMU and 18 inch line in FY-03), thereby eliminating two years of HRC injection that would otherwise be coupled with expensive monitoring and research studies. Excavation would remove technetium-99 (Tc-99) and most of the TCE and U source terms. The excavated material could be treated quickly with soil vapor extraction to treat the TCE, which is classified as 'characteristic' and shipped to off-site disposal as LLRW at Nevada Test Site (NTS). A down gradient drain (Geodrain) or a siphon (Geosiphon) pipe from the bottom of the source excavation to the bottom of the nearby escarpment is also recommended after the source material is removed. This gravity induced pumping of the surrounding aquifer should pull most of the residual contaminated groundwater to one location for treatment or discharge. The drain water could be treated using the existing wastewater treatment facility, if necessary. When the drain or siphon is installed, the previous characterization data could be used to decide if additional lateral horizontal wells from the excavated area might improve control of the residual contaminant plume. The excavation area could also be backfilled with high permeability material and amendments (e.g. reductants \& phosphate). Other options, such as passing drain water through an amendment containing system at the drain outlet prior to release are feasible.

The next step, which could be scheduled to take place at the end of fiscal year 2004, would be to monitor the Geodrain for one year in order to establish trends in groundwater contaminants of concern. If monitoring data indicates a need, the site should consider amendments to reduce residual on-site groundwater contamination levels to allow license termination (e.g. reductants, HRC). If additional amendments are deemed necessary, the site should investigate research and development activities that will provide the best alternatives (such as NABIR, EMSP, SERDP, ESTCP, and others). As part of the longterm strategy, the site could transition the groundwater plume to MNA. The site should also consider a risk-based assessment, especially for the residual uranium contamination. The current approach of biostabilization or any in situ stabilization approach will have to depend on reduction or adsorption in situ. The stabilized (reduced and adsorbed) $\mathrm{U}$ is 
likely to reoxidize and become more mobile at least transiently throughout the plume on long-term basis. Given the lack of risk receptors and the intended permanent industrial use for the site this risk-based assessment of the plume might greatly reduce remediation and monitoring needs and allow the site to terminate the ODH radiation license.

\section{POTENTIAL FOR CONTINUED INVOLVEMENT}

One element in the technical assistance request was the need for the team to provide sustained support to assure that any appropriate recommendations can be successfully implemented. Additional support might involve implementation of recommendations for soil, concrete, and CAMU/groundwater. For example, in soils, the team (or individual team members) could coordinate field screening performance evaluation and demonstrations, work on a closure plan for clean soils generated by excavation, develop closure protocols to address partially buried contamination overlain by clean soils, or integrate GPS/GIS with on-site Trimble (NaI). For concrete, team members could identify data gaps to substantiate cost/benefit analysis for concrete and propose ways to fill gaps, complete a technology assessment to determine the best tools for characterization, or work on decontamination/demolition of the concrete or closure protocols for soils beneath footers/pads if RMI decides to try to abandon in place. For groundwater/CAMU issues, the team could provide characterization support for CAMU activities (CPT, MIP), assistance with design and optimization of Geodrain or Geosiphon, evaluate monitoring data for amendment need or selection, assist in risk assessment, provide links to $\mathrm{R} \& \mathrm{D}$ for amendment selection, design review, readiness reviews, and provide source documentation for precedence, functional design criteria, etc. 


\section{$1.0 \quad$ SOILS}

\subsection{Background/Baseline}

As the AEMP nears completion of environmental restoration, remediation of contaminated soils remains a significant component of the overall program. While the focus of remaining soil problems is Area B, other isolated areas remain that need to be addressed such as the lead and $\mathrm{U}$ contaminated area in Area $\mathrm{C}$. The decision has been made to discontinue soil washing activities at the site. Consequently, all soils above the site's cleanup criteria will need to be excavated and disposed of off-site. The principal contaminants of concern are total U (cleanup criteria of $30 \mathrm{pCi} / \mathrm{g}$ averaged over 100 square meters, with no samples to exceed $90 \mathrm{pCi} / \mathrm{g}$ ) and Tc-99 (cleanup criteria of 65 $\mathrm{pCi} / \mathrm{g}$ averaged over 100 square meters, with no samples to exceed $196 \mathrm{pCi} / \mathrm{g}$ ). Where Tc-99 and total U are collocated (with Tc-99 greater than $6.5 \mathrm{pCi} / \mathrm{g}$ ), a unity rule or sumof-ratios criterion is applied. However, a recent Geoprobe study did not find Tc-99 to be a cleanup driver in any area except the CAMU. Consequently this analysis of approaches focuses on excavation processes to address total $\mathrm{U}$.

Soil excavation has taken place at the site in the past so there is a well-established baseline process for conducting this work. This baseline consists of the following process and technologies. Areas considered impacted are screened using GM direct readings, supplemented with gamma spectrometry of discrete soil samples. Based on these data, excavation footprints are defined. Upon completion of excavation, $\mathrm{NaI} 2 \times 2$ scans are performed to identify remaining areas of elevated activity. Where $2 \times 2$ data is inconclusive, XRF is used to provide more definitive information. When the site is satisfied that cleanup criteria have been met, a final status survey consistent with NUREG 5489 is performed to verify that the surface is in compliance with closure criteria (RMIES SOP Final Survey Plan of Soils, RDP-ESH-029). This consists of four samples taken per 100 square meters with the average compared to the site guidelines. Samples locations are either systematically gridded in each quadrant of the 10x10 grid, or biased if the NaI identifies an elevated area. In addition, samples are pooled and subjected to a student-t test using the $95 \%$ upper confidence level as a point of comparison to the cleanup criteria. The principal issues with this approach as excavation moves into Area $\mathrm{B}$ are:

- More contamination at depth is expected in this area, requiring layback that will include a substantial amount of clean soil unless shoring is used;

- Data sets used to support contaminated-volume estimates lack sufficient detail to provide accurate footprints suitable for excavation design; and

- Scanning technologies currently in use at the site lack sufficient sensitivity to accurately identify total $\mathrm{U}$ concerns around the cleanup guideline. 


\subsection{Critical Issues}

Three broad issues were identified for soils, particularly in Area B. The first issue pertains to how the site will demonstrate compliance with cleanup requirements for "clean" soil excavated as part of the process of getting at subsurface contaminated soils. The second issue is how to demonstrate compliance with cleanup criteria for those areas not requiring remediation, with surfaces that are in compliance, but where there are lingering doubts about the possibility of buried contamination (due to leaking drains, backfill operations, etc.). The third issue relates to the potential for the concrete pads being abandoned in place, and how to establish that soils beneath those pads are in compliance with cleanup requirements.

\subsection{Evaluation of Alternatives}

Two fundamentally different approaches to support soil excavation work were considered. These include (1) an approach that integrates additional data collection into the excavation process to provide for in situ soil segregation as work proceeds, and (2) an approach that emphasizes additional characterization work to address remaining uncertainties in contamination extent combined with the baseline approach to soil excavation. The principal drawbacks for the second approach are:

- Although this may reduce uncertainty about the final expected volume, it will not eliminate uncertainty,

- It may result in over-excavation since the footprint defined by this type of dig will still likely encompass clean soils unnecessarily.

Consequently the first alternative was selected as the preferred alternative.

\subsection{Recommendations}

\subsubsection{Approach}

The approach for the preferred alternative is based on integrating "real-time" data collection into the excavation process, and using these data to address the uncertainties inherent in the actual footprint of contamination. In this approach, areas are identified that are known to need remediation based on all available current information. Excavation would be conducted sequentially with "lifts" or "layers" of soil removed. After excavating each lift, data collection would take place over the exposed dig face to determine the contamination footprint within that dig face. A variety of technologies can be used for this (see section 1.4.3). Work would proceed until all known or encountered contamination has been identified. Soils generated by this excavation process are segregated by whether they have exceeded the cleanup criteria based on real-time data. Clean soils could be used for backfill, assuming sufficient information was collected to satisfy closure requirements. To be successful, this approach requires data collection technologies with sufficiently low detection limits to support the segregation of soils at 
$30 \mathrm{pCi} / \mathrm{g}$ for total $\mathrm{U}$, and an excavation logic that provides sufficient time for dig-face screening to take place without jeopardizing excavation efficiency. The USACE FUSRAP program has successfully adopted this methodology to address $U$ contamination in soils.

\subsubsection{Rationale}

The advantages of this approach are that it allows spending to focus on remedial efforts rather than additional characterization; provides an efficient means for addressing uncertainties present in the contamination footprints; minimizes the possibility that clean soils are inadvertently excavated for off-site disposal; and provides at least some of the information that would be required for reusing excavated clean soils as backfill.

\subsubsection{Technology Options}

The principal technology requirements for implementing this approach focus on dig face characterization technologies. Individual technologies and their characteristics are contained in the technology matrix presented in Table 1.4.3. Technologies fall into basically four categories:

- Discrete sample analytical techniques (either XRF or gamma spectrometry) with quick turn-around times. Pro: accepted by regulators, known data quality, site already has equipment. Con: point measurements, relatively expensive and time consuming.

- In situ direct measurement techniques based on HPGe systems. Pro: real-time results, detection limits well below $30 \mathrm{pCi} / \mathrm{g}$, commercially available. Con: Expensive equipment, trained operators required, 15-20 minute acquisition times.

- Mobile scans with large-crystal NaI gamma spectrometry systems (RSS, RTRAK, Gator as used as Fernald). Pro: real-time results, complete coverage of exposed surfaces, detection limits likely below $30 \mathrm{pCi} / \mathrm{g}$. Con: not commercially available, data of more uncertain quality than HPGe, potential mobility problems on rough dig faces.

- Mobile scans with FIDLER systems. Pro: excellent mobility, low cost solution, commercially available. Con: potentially questionable detection limits for U.

The last two options presume that they are combined with a GPS and a data logging system for capturing information collected. In the case of HPGe and FIDLER systems, the technologies and supporting services are readily available either via subcontracting or through the larger DOE community. In the case of the large-crystal mobile NaI systems in use at Fernald, either the equipment would have to be loaned by Fernald, or a custom system built for the site. 


\begin{tabular}{|c|c|c|c|c|c|}
\hline 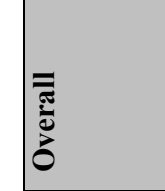 & 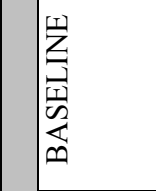 & 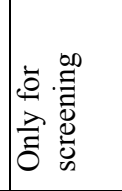 & $\mid \begin{array}{l}\overrightarrow{0} \\
\dot{0}\end{array}$ & 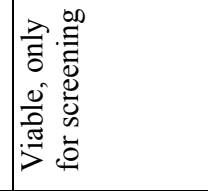 & \\
\hline 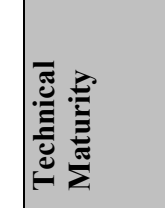 & 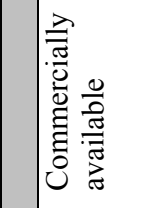 & 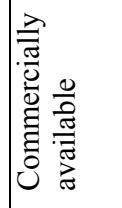 & 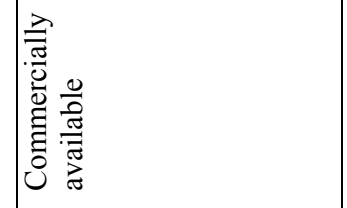 & 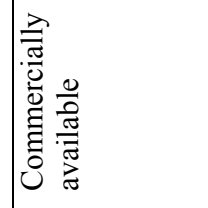 & 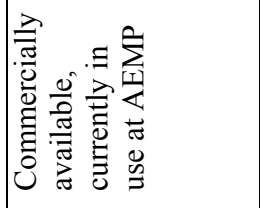 \\
\hline 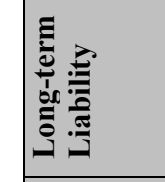 & 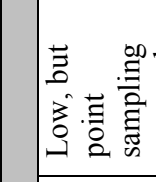 & 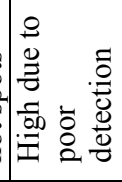 & 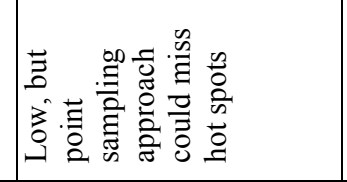 & 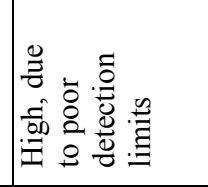 & 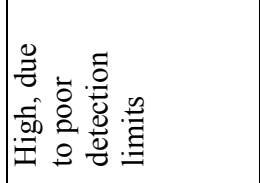 \\
\hline 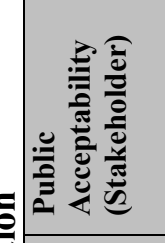 & 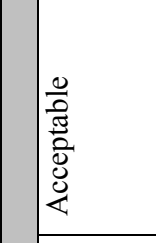 & 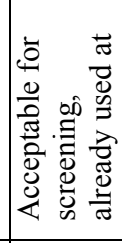 & 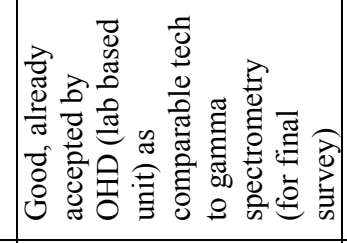 & & 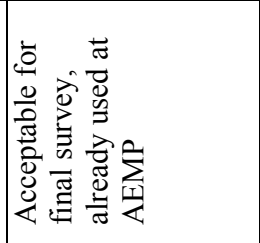 \\
\hline Uे & 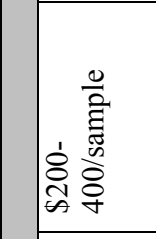 & 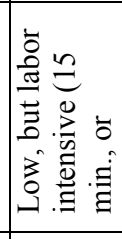 & 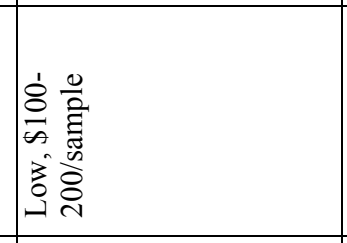 & & 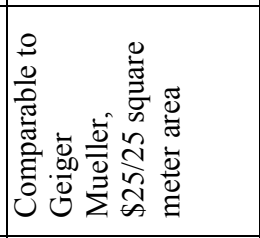 \\
\hline 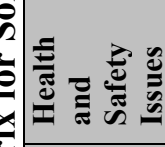 & 蒿 & 产 & $\mid \begin{array}{l}\ddot{g} \\
\ddot{z}\end{array}$ & 劳 & 蒿 \\
\hline 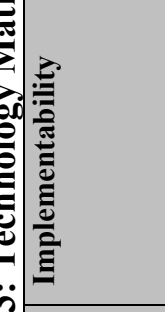 & 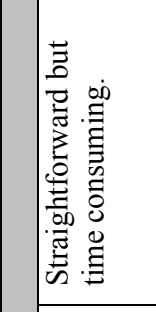 & 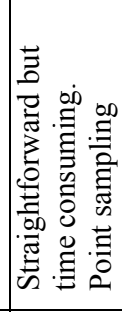 & 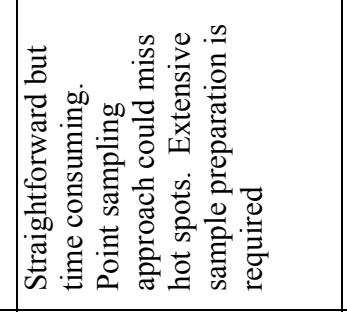 & 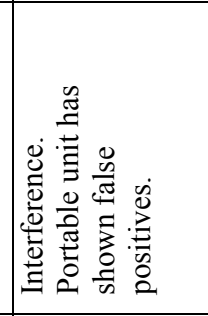 & 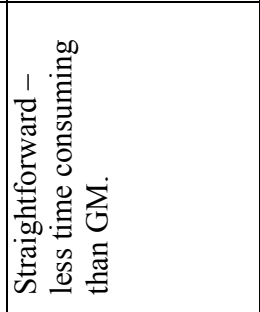 \\
\hline 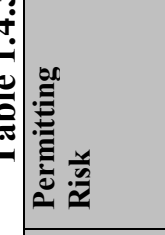 & 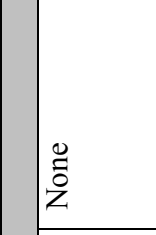 & 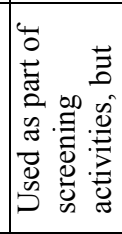 & 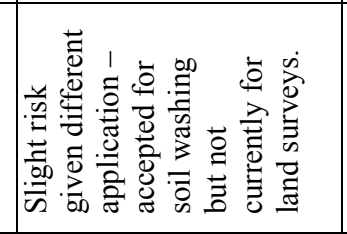 & 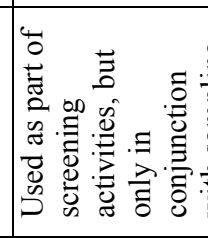 & 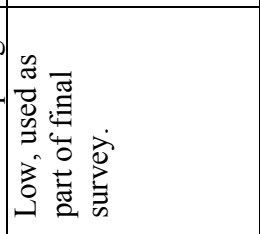 \\
\hline 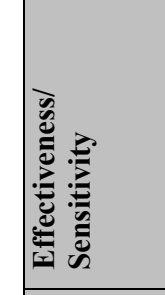 & 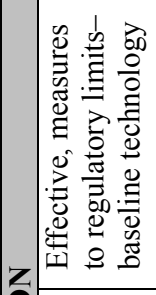 & 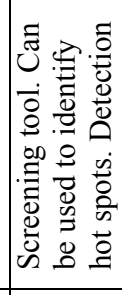 & 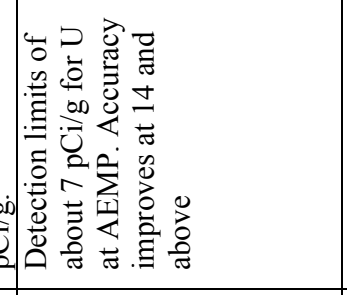 & 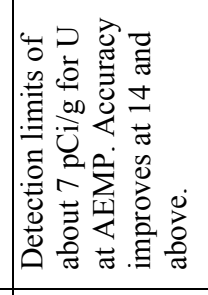 & 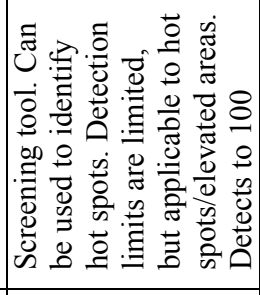 \\
\hline 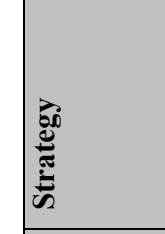 & 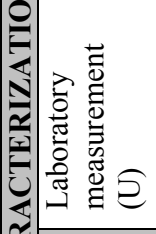 & 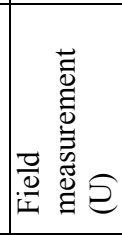 & 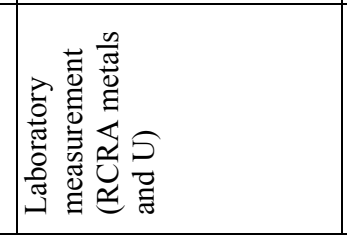 & 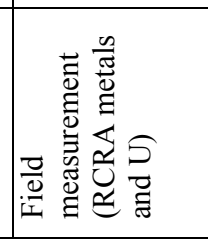 & 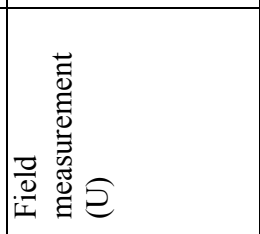 \\
\hline 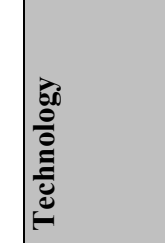 & 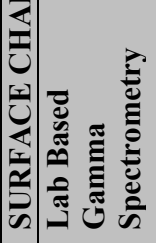 & 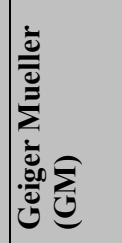 & 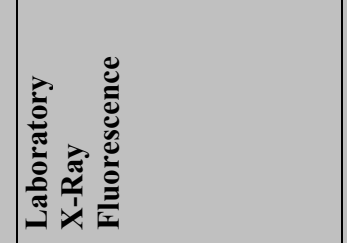 & 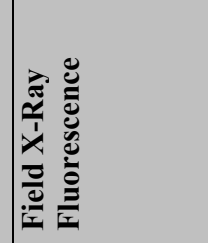 & 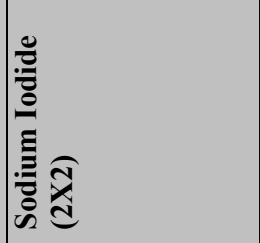 \\
\hline
\end{tabular}




\begin{tabular}{|c|c|c|c|c|c|c|}
\hline 彦 & 莺 & 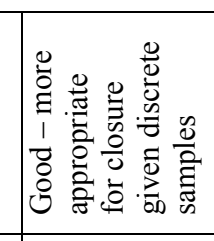 & 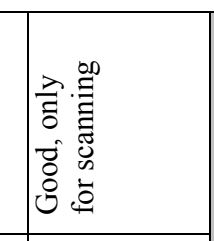 & & 总 & 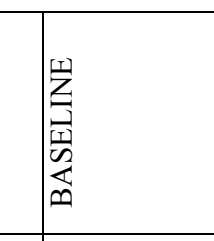 \\
\hline 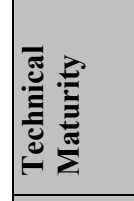 & 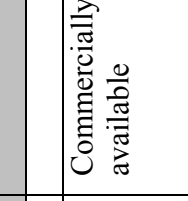 & 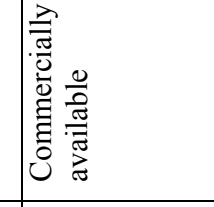 & 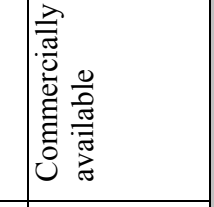 & 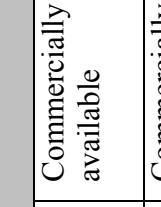 & 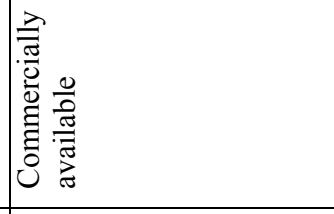 & 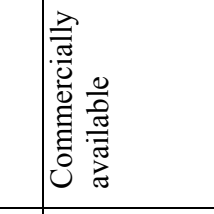 \\
\hline 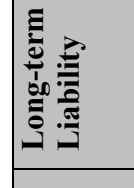 & 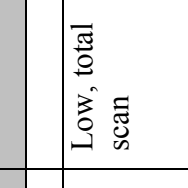 & $\overline{3}$ & 3 & & 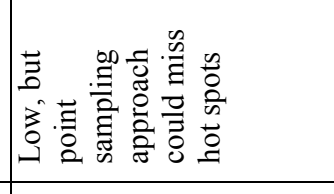 & 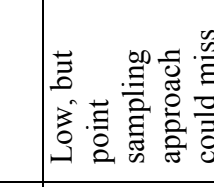 \\
\hline & 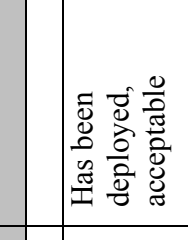 & 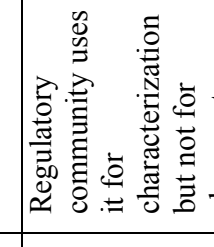 & & & 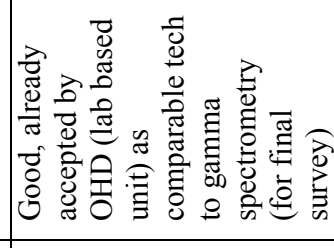 & 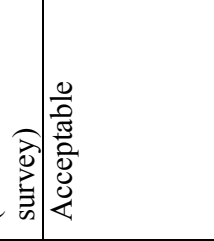 \\
\hline$\frac{5}{8}$ & 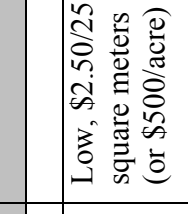 & 等言言言 & 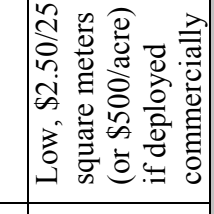 & & 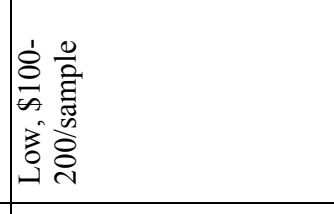 & 童 \\
\hline 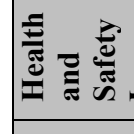 & : & 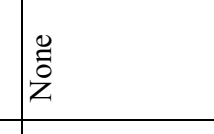 & 产 & 言 & 产 & $\frac{0}{\bar{z}}$ \\
\hline & 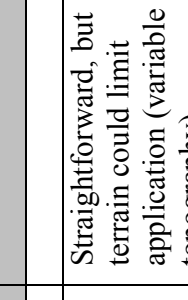 & 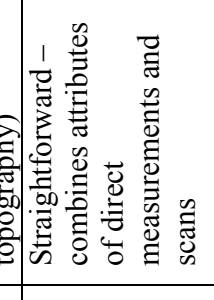 & 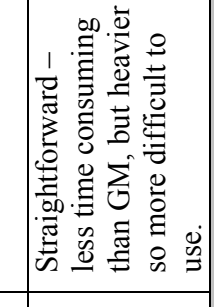 & & 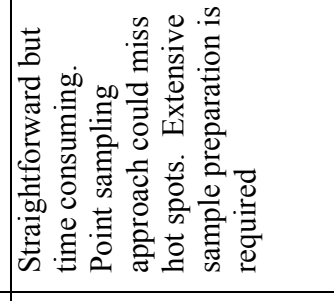 & 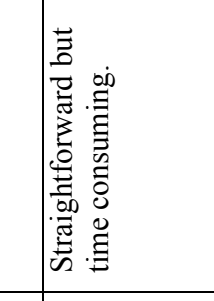 \\
\hline 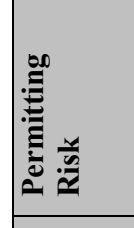 & 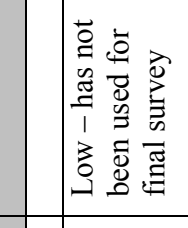 & 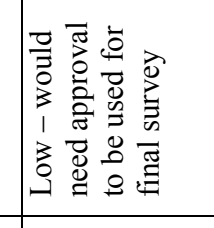 & 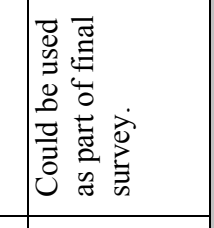 & & 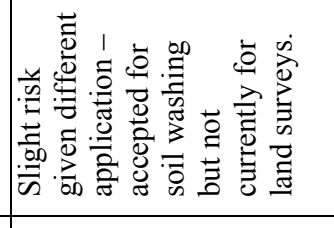 & 总 \\
\hline & 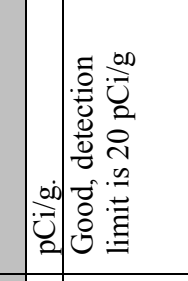 & 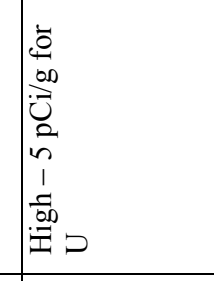 & 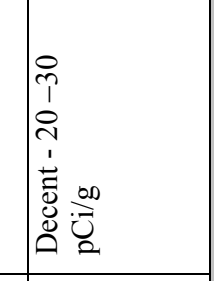 & 亨 & 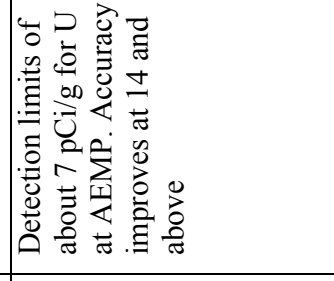 & 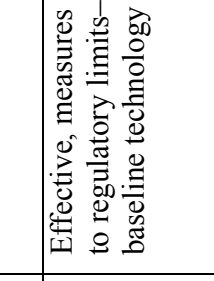 \\
\hline & 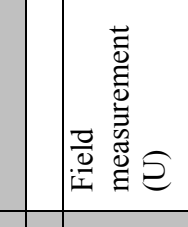 & 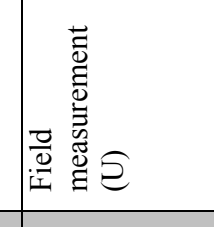 & 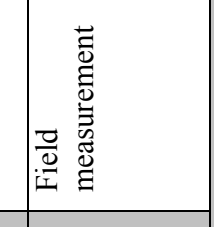 & 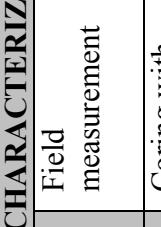 & 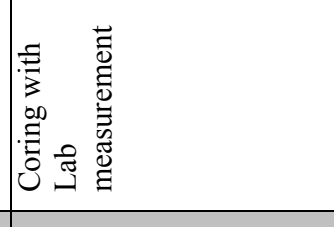 & 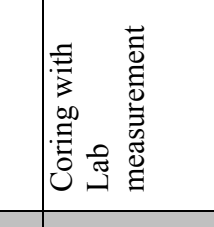 \\
\hline & 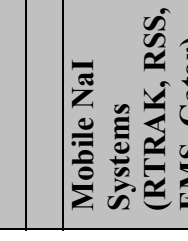 & 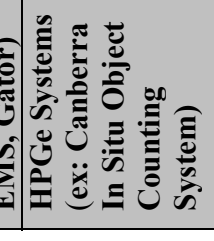 & 离 & 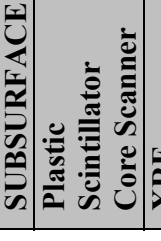 & & 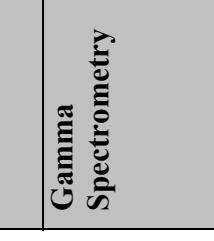 \\
\hline
\end{tabular}




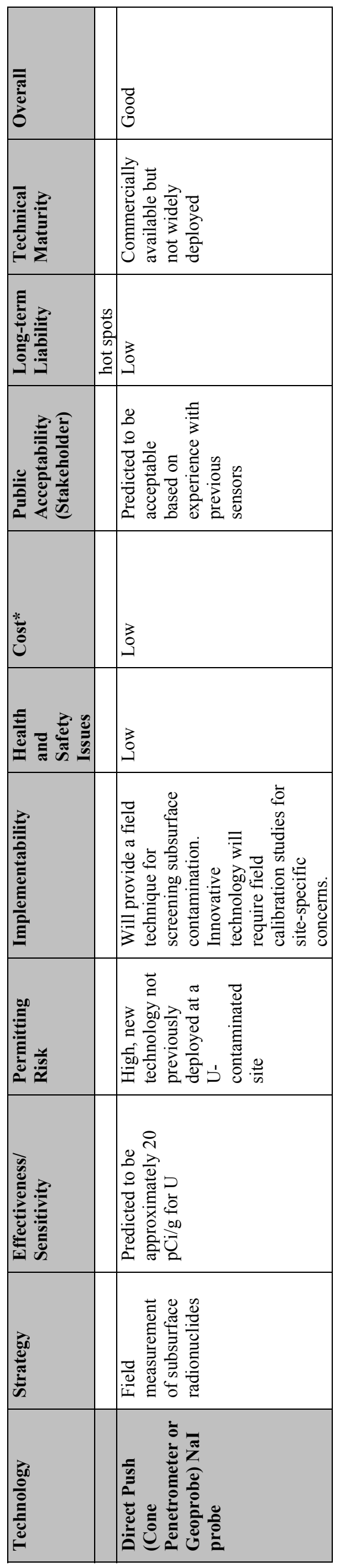

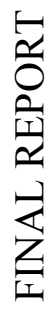




\subsubsection{Unresolved Issues}

To implement the recommendations, the following issues will need to be addressed:

- An acceptable method will need to be established for demonstrating compliance with cleanup requirements for soil segregated as clean.

- An acceptable method will need to be established for demonstrating that buried contamination does not exist for areas where this might be of concern.

- An acceptable method will need to be established for demonstrating that soils beneath pads abandoned in place meet site cleanup requirements, in the event that pads are left behind.

- The optimal suite of technologies will need to be identified, their performance characteristics documented for the site, and site-specific standard operating procedures (SOPs) developed.

- In the case of NaI scanning technologies, trigger levels will need to be determined that can be used for reliably segregating clean soils from contaminated.

- Appropriate lift sizes will need to be determined.

- An excavation logic will need to be developed for the site that will govern how excavation work is conducted.

Note that the first three bullets above are broad unresolved issues that need to be addressed regardless of whether characterization/remediation recommendations in this report are implemented.

\subsubsection{Action Items}

As a first step, AEMP should bring potential technology candidates to the site and review their performance using the lead area in Area $\mathrm{C}$ (which also has $\mathrm{U}$ contamination), portions or all of Area F, and portions or all of area D. Specific items to address are detection limits and operational characteristics or constraints that may impact their use at the AEMP. Candidates for inclusion would be an HPGe system, one of the mobile NaI systems from Fernald, and a FIDLER or miniFIDLER system. In the case of the last, it is important that the system deployed be combined with a GPS and a data logging system.

Site-specific SOPs are needed for the selected technologies at the site. These could be modifications of existing SOPs for similar equipment in use at other sites such as FEMP or ORNL. In addition, there is a need to develop and negotiate acceptable protocols for the following:

- Soils excavated as layback that are believed to be clean

- Areas with the potential for buried subsurface contamination

- Soils beneath pads and footers if it is determined that pad/footer abandonment is an option for the site.

- Excavation approach that incorporates dig face screening. 


\subsection{CONCRETE}

\subsection{Background/Baseline}

The current baseline approach calls for removal of all concrete (slabs and foundations) and asphalt for off-site burial as low-level waste except for the ten buildings RMI would like to maintain. The current estimated amount to be shipped is 114,900 cubic feet.

\subsection{Critical Issues}

There is no release procedure to clear the ten buildings RMI would like to remain in place. The amount of effort and cleaning required to release these buildings in place may be more costly than a total demolition. This concern applies to the last two options presented below.

Although RMI's cost benefit analysis showed treating the slabs as contaminated was more cost effective than trying to decontaminate and segregate the clean portions, this does not necessarily apply to the foundations of the buildings. In addition, there may be certain technologies that will decrease characterization and decontamination costs and other waste disposal options.

General consensus (State of Ohio, RMI) has been that the concrete slabs (other than the questionable ten buildings) cannot be left in place. It is felt that leaving them in place will make a $100 \%$ final release survey too difficult and imparts a risk of missing something.

The waste disposal plan calls for sending all of the low-level waste to Envirocare. Although several site people indicated that other disposal locations had been evaluated, no documented information was available to definitively show that Envirocare was the best disposal location. The disposal at this location requires that the concrete must be processed into small pieces. Other disposal locations should be evaluated. For instance, it may be possible to send concrete contaminated up to $150 \mathrm{pCi} / \mathrm{g}$ to the Waste Control Specialists site in Texas (for NORM) by modifying the current radioactive materials license.

The extent of the contamination on the concrete slabs and footers is not well documented/known, making it very difficult to make accurate assumptions about the cost of decontaminating, etc. Additional information is required to be able to choose which alternative is the least costly and will accelerate the schedule.

\subsection{Recommendations}

The team detailed three options that might be pursued by the site for concrete disposition. The approach, rationale, technologies, short/long-term actions and issues associated with each of three options are presented below. 


\subsubsection{Option 1}

Option 1 assumes all concrete is contaminated, and calls for removing and disposing of all concrete as low-level waste. This includes disposing of concrete associated with the ten buildings that RMI has earmarked as potentially remaining in place. This alternative ensures DOE has no remaining liability with RMI or the State of Ohio in this area.

Demolition technologies that can more quickly and efficiently remove the concrete slabs and footings should be investigated. Potential technologies might include looking into using the OST "Universal Demolition Processor" deployed at Fernald, the Hammerhead deployed at the INEEL, or equivalent technologies. In the short-term, the site should obtain information on rates for various concrete processing equipment to determine ballpark costs and processing rates. Even if this work is sub-contracted, this information would allow a more accurate estimate of the total cost of the process.

\subsubsection{Option 2}

Option 2 calls for segregating some of the concrete as clean since it may be more cost and schedule effective to clean and leave certain large volume pieces of concrete in place. All slabs would be treated as contaminated except the slabs under the ten buildings RMI wants to maintain (which must be free-released). The footing for the extrusion press would be decontaminated and buried in place after being verified clean. Other verified clean large pieces of foundation will also be buried in place and some decontamination may be considered if economical.

In the short-term, the site should obtain detailed information on the extent of contamination. Mapping of currently available information should be completed to determine where more surveying/sampling needs to be conducted. Further information could be obtained as needed to complete an adequate picture of contamination on both slabs and footings and in the ten buildings RMI would like to keep. Innovative technologies, such as the Shonka Surface Contamination monitor or the OST developed survey and scabbling equipment from Florida International University (FIU), could be used to determine whether a significant portion of the concrete can either be free-released as is or if they can easily and economically decontaminated to free-release standards. If the exposed surfaces show promise then the OST "Hollow Core Drill" technology demonstrated at Mound can be used in conjunction with other sensor/sampling technology to verify the underside of slabs and foundations are clean. The site should also examine locations where piping and underground utilities (that will have to be removed) go through the foundations and map them to show where footings will have to be removed. In addition, the site should optimize equipment used for characterization, decontamination and demolition by completing a technology matrix on this type of equipment. Production rate and cost information on a large variety of technologies is available from past DOE Large Scale Demonstration and Deployment Projects and Accelerated Site Technology Deployment Projects. There are also several web sites, such as FIU's GET site that have the information to suggest the "best" way of completing 
the work. Moreover, the site should reevaluate waste disposal options, develop a protocol for releasing the ten buildings as there is a cost for the additional sampling and approvals, and develop a protocol for leaving the concrete footings in place.

In the long-term, an independent cost benefit evaluation should be completed using information obtained by completing the short-term recommended actions. It is estimated that completing all the short-term actions and this cost benefit analysis may cost on the order of $\$ 50 \mathrm{~K}$. However, a savings on the order of $\$ 1$ million over the baseline may be possible.

In addition to the overall issues noted previously, some of the unresolved issues associated with this option include the following:

- Although not disallowed by the decommissioning plan, leaving uncontaminated buildings and underground concrete is not specifically addressed and written authority will need to be obtained. This may be as simple as a letter of correspondence between ODH and RMI.

- There is also no current procedure to clear the footings for free release. However, there is precedence in the State of Ohio to verify footings clean and bury them in place (reportedly).

- Under the current contract the ten buildings and the uncontaminated concrete is not allowed to be left in place and will have to be agreed upon through contract negotiations between DOE and RMI.

\subsubsection{Option 3}

Option 3 is to decontaminate as much as is feasible and segregate the concrete. Some of the clean concrete would be crushed and disposed of at the local landfill or used as onsite fill material. Clean footings would be left in place. All contaminated concrete would be crushed and sent to a LLRW site.

Short-term and long-term recommended actions for Option 3 are the same as those presented for Option 2 (see section 2.3.2). Unresolved issues are the same for Option 2; however, it should also be noted there is some resistance from the local landfill (and possibly other stakeholders) to placing any concrete into the landfill that was in a previously contaminated area even if it has been declared clean.

\subsection{Overall Recommendations}

In order to narrow the options down to a preferred alternative, more cost information is needed. The amount of decontamination and handling prior free-releasing any concrete is key to determine which of these options is most cost-effective for AEMP. In the shortterm, it is recommended the site obtain detailed information on extent of contamination by first mapping existing surveys to determine where more surveying/sampling needs to be conducted. Also the locations where piping and underground utilities (that will have to be removed) go through the foundations should be mapped to show where footings 
would have to be removed. The site should take steps to optimize equipment used for characterization, decontamination and demolition by completing a technology matrix. Options for waste disposal should also be investigated and documented. To leave the ten buildings in place, protocols for releasing buildings must be developed, as there is a cost for the additional sampling and approvals. A protocol for leaving the concrete footings in place is also needed.

When these short-term actions are complete, an independent cost benefit evaluation and a timeline should be completed using this information. It is possible that although one option may be cheaper it may also add significantly to the decommissioning schedule, which may or may not be desirable. It is estimated that completing all the short-term actions and this cost benefit analysis and timeline may cost on the order of $\$ 50 \mathrm{~K}$. However, a savings on the order of $\$ 1$ million over the baseline may be possible.

\subsection{CAMU/GROUNDWATER}

\subsection{Background/Baseline}

This technical assistance request sought evaluation, recommendation, development, and application of a process to treat source material of approximately 6,600 cubic yards of soil/sediment contaminated with organic solvents (TCE), Tc-99, and U in the CAMU and associated groundwater plume. The source area to be removed would be much larger if the TCE source is to be reduced to less than $23 \mathrm{mg} / \mathrm{kg}$.

\subsection{Critical Issues}

Critical issues in for CAMU/groundwater include the following:

- Conceptual Model: Need to refine and document conceptual model of contaminant distribution and migration mechanisms, plume structure, and opportunities for focused remediation.

- Source removal: When and how quickly can this be done. How can this be integrated with schedule for building demolition?

- Well Network: Defining an appropriate package of wells for monitoring the different phases of cleanup. This includes evaluating existing wells and infrastructure that can be used and wells that might be added or abandoned. Need to complete development of maintenance and replacement lists. Think about long-term network in terms of sentinel well system or alternative (e.g., monitoring in evaporation ponds or in a central large-scale collection system).

- Flow in permeable zones: Develop iterative process of focusing on permeable flow paths that will lead to more rapid remediation. These flow paths include utilities, 18" storm line, and natural sand lenses in clayey till.

- U, Tc-99, and TCE: All need to be addressed in source efforts. In situ TCE treatment methods could reduce volume to be excavated by half if only radionuclides source needs to be excavated. Ex situ TCE treatment using simple soil vapor extraction is faster, cheaper, and would potentially have less impact on closure schedule. 
- Groundwater target: The targets for groundwater contaminants are not risk based, they have all been set at the MCL for unrestricted use. If the site is only to have industrial uses in the future, these endpoints are too low and costly to attain. Are there alternatives? Groundwater standards are not consistent with soil standards and will thus require an extended period of treatment after excavation - likely to extend beyond 2006.

- Recognizing the scale of the problem and the low quantity of contaminants: It is important to match the action to the size of the problem, especially since source excavation and off-site disposal is planned.

- Implement demonstrable MNA concept for long-term plume solution: Couple destruction of organics and biogeochemical stabilization for radionuclides into a phased approach that would proceed from aggressive engineered treatment to passive treatment strategies to monitored natural attenuation.

- Other (non CAMU) sources: evaluate current information on non-CAMU exceedances of standards and contaminant hits. Implement recommendations (low flow pumping, reinstallation of wells, and the like) to confirm that hits are representative and develop appropriate responses.

\subsection{Unresolved Issues}

The site will need to determine whether TCE needs to be treated prior to sending to Envirocare (soil is believed to be destined for Subtitle $\mathrm{C}$ landfill with/without TCE). If it needs to be treated, there is a need to consider treatment during staging after excavation. The site should revisit soil vapor extraction of the excavated soil and related technologies. One option might be to treat the excavated source material and move it to the Nevada Test Site as low-level waste.

It is uncertain whether the barium in the shale wells is naturally occurring, associated with drilling muds or other well installation issues, or is process related. More information is also needed to understand the presence of lead. Lead could be present in glacial till (well 511) from flow in the well annulus after damage by heavy equipment. Lead found at greater depths (several wells broadly distributed) could be from suspended solids, unusual weathering products from shales, or grout contamination. The team felt that many of these wells were contaminated by grout (but this needs confirmation) and that these wells should be candidates for abandonment and replacement as needed.

The team also felt that there is significant uncertainty associated with the rates and completeness of bioreduction of TCE that will be stimulated by the hydrogen release compound (HRC) interim action that is currently in progress. The low permeability associated with these soils and the low flow rates observed in these groundwaters would suggest that it may take a very long time to stimulate bioreduction of TCE. The bioreduction and stabilization of $U$ in this environment is also uncertain as is the rate of reoxidation that might occur after the HRC is depleted.

Another issue that should be addressed is the willingness of ODH to accept risk-based assessments of impact of $U$ contaminated groundwater at the site on a long-term basis. 


\subsection{Baseline Technology}

The current baseline technology for the site had been TCE source area bioremediation, excavation of radiologically contaminated soils and soil flushing to remove residual TCE, U, and Tc-99 from contaminated groundwater. However, it was found that this process did not adequately remove the $\mathrm{U}$ from the soil. Recently it was decided to switch to in situ bioremediation of TCE in the source area as an interim action, followed by excavation of $U$ and Tc-99 contaminated soils in the CAMU and disposal of the removed material in a secure landfill at Envirocare. This action was taken since the removed material would be considered a mixed waste, a much greater disposal cost. The in situ bioremediation of the TCE was deemed prudent since the area to be excavated would impact the foundation of a nearby building and the building was not due to be removed for some time. Additional injection of reducing agent and possible injection of chemical fixation agent such as a phosphate source are also being studied.

\subsection{Evaluation of Alternatives}

After a discussion with site personnel about the technologies previously considered, the team developed a list of potential technologies to be further evaluated for both the source area and the residual groundwater plume. The technologies evaluated for the CAMU source and the dilute groundwater plume are discussed below, and are presented along with technology matrices that examine the technologies in terms of effectiveness, regulatory and stakeholder issues, health and safety issues, technology maturity and other factors (see Tables 3.5.1 and 3.5.2).

\subsubsection{CAMU Source Remediation}

Excavation of Source and Direct Disposal. The excavation and direct disposal option assumed collection, packaging and transportation of contaminated soils to an off-site disposal facility. The facility would have to be capable of accepting the untreated soils in their current state (e.g., with radionuclides and volatile organic compounds). Off-site disposal was recognized as a rapid and complete approach to permanently remove the contaminated soil from the Ashtabula facility and was evaluated in terms of Ashtabula closure goals (cost and schedule). This disposal option was determined to be compatible with Ashtabula schedule needs; however, cost was estimated to be relatively high based on the assumptions that the soil would need to be packaged at Ashtabula, transported to the selected disposal facility and disposed as mixed waste. However, a significant cost savings might be realized if the excavated material was treated for VOCs after excavation and redesignated as low-level waste. This option may be difficult to implement since the 'derived from rule' for listed RCRA waste appears to apply for both Ohio and Utah, the potential off-site disposal facility location. However, TCE could be treated by bioremediation in situ or by some desorption method ex situ, allowing it to be disposed as LLRW at NTS if the TCE in the excavated source material was classified as RCRA 'characteristic'. This is only a hypothetical alternative at this point, but may be worth evaluation for the potential savings. Similarly, disposal at one of the Fernald on-site cells 
is not believed to be an option at this time, but the potential for cost savings makes the option worth evaluation. It also appears that the earlier concerns of excavation near the building may not be an issue since the impacted building is on a much faster decommissioning schedule. However, even if the building was still impacted by excavation activities, it is also possible to use other excavation techniques like auguring and caisson placement to minimize effect on the nearby building foundation. Thus, offsite disposal of the source zone material was determined to be the best alternative and could potential greatly speed up the schedule.

Stabilization. These methods include slurry walls, caps, sheet pile walls, grout injection/mixing, silica gel injection, and related geotechnical techniques. These techniques attempt to stabilize and address solvents, metals and radionuclides by removing them from the active transport pathways in the soil and groundwater system. Because of the low concentrations needed to meet regulatory goals (e.g., $\mathrm{mg} / \mathrm{L}$ or ppb levels) for the solvents, isolation methods have not been successful to date. Thus, they are listed here for completeness and a commercial variant has not been identified. Even the carefully installed sealed sheet piles at the Borden site in Canada did not successfully eliminate the contamination of surrounding groundwater after source solvent was added inside the test cell in a controlled experiment. Based on the monitoring data, the VOC source in the CAMU is not migrating rapidly and much of the residual source appears to be trapped in lower permeability sediments in this heterogeneous system. Despite these relatively favorable conditions for source zone isolation methods, the technical assistance team does not recommend these methods for the CAMU source because of the poor effectiveness as a long-term solution, especially for the VOCs, and the very low stakeholder/regulatory acceptability.

VOC Oxidation. Chemical oxidation uses reagents to destroy high concentrations of contaminants (typically non-aqueous phase liquids). Because in situ oxidation requires delivery of reagent and requires intimate contact of the reagent with the source solvents, it would work well in an excavated soil system where the geometry and flow characteristics could be carefully controlled but would not work well in situ at the CAMU because of the poor permeability of the sediment. Also, because it is an aggressive and rapid method, such a treatment would be able to meet schedule requirements (assuming that a system could be set up and operations started in a timely fashion). Typical treatment reagents include Fenton's reagent (hydrogen peroxide and reduced iron) and permanganate solutions. These reagents are strong oxidizers that "burn" the contaminant in a saturated or moist soil setting. As the reagent is added, it reacts vigorously and often induces bubbling and mixing - a process that may enhance contact of the reagent with the target contaminant. Several variants of in situ oxidation methods have been deployed commercially. A key element to the success is performing the work rapidly with a minimal volume of reagent. Specific attributes that make this technology promising includes: relatively small and well-defined highly contaminated and permeable target soils. The technology uses large volumes of dangerous reagents, is moderately difficult to deploy (i.e., requires expensive infrastructure), requires moving and mixing the soil, requires low ambient $\mathrm{pH}$ for Fenton's reagent, and many similar challenges. This technology will also reoxidize reduced forms of uranium, U(IV), chromium (III), and 
other metals, which are relatively insoluble. Reoxidation not only transforms these metals and actinides into the more soluble forms $\mathrm{U}(\mathrm{VI})$ and $\mathrm{Cr}(\mathrm{VI})$, but also makes them more toxic in the case of $\mathrm{Cr}$. This increased mobility could also become a handling issue even during and ex situ treatment process, in terms of disposal of the leachate. Since safer, less-expensive, and effective alternative technologies are available, chemical oxidation is not recommended.

Electrochemical. Electrochemical Treatment is a recently proposed and implemented technology that uses electrical current as the central component of a system to decontaminate contaminated soil in place. Similar to the more aggressive direct energy thermal techniques (e.g., six phase heating and radiofrequency heating), these treatments rely on injecting electromagnetic energy directly into the bulk soil. Thus, the considerations of geology, water content, etc are similar with these methods as with the related thermal methods. The key difference in these "treatment" methods is the additional implementation and documentation of a destruction or detoxification mechanism in the deployment process. Two variants, at different levels of maturation are discussed below. These are the Lasagna technology and the ElectroChemical Remediation Technology (ECRT).

The most successful electrochemical treatment to date is the Lasagna system developed and implemented by a consortium from federal researchers (DOE, EPA and others) industry and universities. Lasagna is primarily an electroosmosis process that relies on moving water through the subsurface. This technology exploits phenomena in which ions in the diffuse double layer near soil particles move in response to a DC electric field and induce water movement in a parallel direction via shear forces or drag at the double layer interface. The unique feature of Lasagna is placing layers of treatment or capture material in the path of the moving water so that the contaminants are efficiently detoxified as they move over relatively short distances. The system also minimizes the problems sometimes associated with the chemistry near the electrodes by treating the contaminants relatively far away within the target treatment volume. While the basics of this technology are well established from industrial applications in dewatering and clay consolidation, fully reliable performance for remediation applications has yet to be established. The technology is most applicable to saturated or near saturated sediments with low permeability (e.g., $<10^{-5} \mathrm{~m} / \mathrm{s}$ hydraulic conductivity). Within this bound, the method has low power consumption and will induce a relatively uniform flow that is "independent" of heterogeneity. For organics, the method is limited to the soluble fraction and will not remove residual nonaqueous phase solvents in the system nor will it treat tightly bound contaminants.

ECRT is a recent technology that has been investigated in Europe (P2-Soil Remediation, Inc) and in the United States (by Weiss and Associates in partnership with the developers). The technology advocates suggest that soil can be decontaminated using much lower current densities than Lasagna or heating methods. In particular, they indicate that organics such as TCE can be effectively treated in place by "induced oxidation" processes that they designate Electrochemical GeoOxidation (ECGO). The 
claims are supported by patents (US 5,738,778 and 5,596,644) and by limited field data. Importantly, the developers do not have controlled documentation about the destruction process and do not know mechanism of destruction nor its robustness. They speculate that "these reactions occur at any and all interfaces within the soil" and that "an induced polarization field is produced ... \{leading to $\}$... disharges of electricity to occur ... \{and that $\}. .$. in the electrical discharge, REDOX reactions take place." It is unlikely that "discharges" are occurring at the power densities employed and significant additional research is needed before this method can be reliably used. As with most other direct energy processes, the data suggest that reaction rate is inversely proportional to grain size and that moisture in needed in the system. Based on the case studies, the proposed technology is intriguing and, if substantiated by additional research, may be important in the future. Despite their isolation and available environmental, the conditions in the CAMU do not appear ideal for ECRT/ECGO. The geochemical conditions appear substantially different from those of the anecdotal studies reported to date. Most importantly, however, the technology is sufficiently immature that the project could not be performed in any mode except a research mode - significantly increasing costs for monitoring and incurring potential schedule risk. Based on the available information, this technique would be viable if it performed as claimed by its vendor. These claims appear optimistic and deployments should be selected carefully to minimize potential downside risks if the technology fails while at the same time encouraging disciplined technology development for this type of inexpensive and potentially revolutionary method. According to Weiss Associates, the active redox zone reacts and destroys organics while metals migrate to both electrodes for easy collection and removal. Treatment is reportedly cost effective, but does take months and requires wetting of the soil volume being treated. Despite the reported track record in Europe, the team did not recommend this technology because of its immaturity and its limited track record. Even if the technology works, understanding of the basic mechanisms is limited despite the explanations in the vendor literature.

Bioremediation. Anaerobic bioremediation is a well-proven technology in which anaerobic microorganisms degrade chlorinated solvents by the mechanism of reductive dehalogenation. The pathway for this mechanism includes the degradation intermediates dichloroethene, vinyl chloride and ethene. There is data from groundwater wells in recent history that these degradation products were present. This microbial activity requires strongly anaerobic conditions and the presence of anaerobic microorganisms possessing reductive dehalogenation capability. In cases where natural conditions do not support active anaerobic reductive dehalogenation, it is common to deploy biostimulation (addition of carbon sources to produce anaerobic conditions) as well as bioaugmentation (addition of anaerobic halorespiring bacteria) to achieve in situ anaerobic biodegradation of chlorinated solvents. Correct conditions and the presence of appropriate biocatalysts will commonly result in complete degradation of chlorinated solvents.

Application of anaerobic bioremediation for in situ treatment of contaminated soils at Ashtabula would require that strong anaerobic conditions be established and maintained. This could be done by exclusion of oxygen, but more likely by biostimulation with excess organic nutrient supplementation. Biostimulation would also result in the 
reduction of additional electron acceptors, including nitrate and sulfate. Additionally, the bioprocess conditions would need to be held within acceptable ranges for temperature, $\mathrm{pH}$ and moisture. Macronutrient additions (primarily nitrogen and phosphorous) may also be required. For in situ biostimulation at the CAMU in the source area the greatest problem will be the low permeability of the soil. Hydraulic conductivities of $10^{-4}-10^{-7}$ $\mathrm{cm} / \mathrm{sec}$ are minimally acceptable for any type of liquid injection. However, in situ stimulation of bioreduction has the added advantage of being capable of reducing $U$, and making it less soluble and hence stabilizing it in situ. The effectiveness of biostabilization strategies for $U$ have a uncertainty as to their long-term stability and their effectiveness under normal environmental conditions, though laboratory studies show great promise. HRC or hydrogen release compound has already been injected at the site and was a good choice as an electron donor for biostimulation of indigenous microbes. $\mathrm{HRC}$ is a polylactate compound that slowly releases lactate when mixed with water. The released lactic acid stimulates both aerobic and anaerobic microbes by providing a carbon and energy source. Anaerobic microbes ferment the lactic acid into pyruvic acid and then to acetic acid, releasing 2 moles of molecular hydrogen per mole of lactate.

Investigations conducted by Regenesis, Ltd. showed that the slow release characteristics of HRC cause reducing conditions to be maintained for a long time (up to 18 months) with a single HRC application. This is a cost effective aquifer treatment as compared to other remediation technologies, in aquifers where it is applicable and time is not a constraint.

Since it is possible that indigenous microbial populations under anaerobic conditions may not degrade chlorinated solvents or only partially degrade them. The past detection of undegraded chlorinated solvent intermediates (e. g., cis-DCE and vinyl chloride) in groundwater at Ashtabula indicates this may be problematic. Partial microbial degradation could result in significant production of degradation intermediates that have a significant lower WAC than the original chlorinated solvent(s). Anaerobic microorganisms typically grow slowly and the time required to get to a reasonable cleanup goal could be excessive. During implementation of the bioremediation project, a contingency was developed to address problems regarding the buildup of intermediates such as cis-DCE and vinyl chloride. SEC and Regenesis believe it is very unlikely that any buildup will occur based on previous experience in similar geologies. However, they did include a contingency to utilize Oxygen Release Compound (ORC) to force the system aerobic and promote the rapid breakdown of the intermediates in situ, if necessary. This contingency has similar problems with HRC in that it requires injection material into a low hydraulic conductivity environment. The aerobic conditions would also be subject to the same nutrient limitations as the anaerobic environment. In addition, the effect of reduction of the $U$ to less soluble states would be reversed, and thus increasing the mobility of the $U$ into the groundwater. Although anaerobic bioremediation of chlorinated solvents is a robust and proven technology, it is not recommended for the CAMU source due to the time constraints, before the source area would be excavated and the uncertainty of its ability to reach reasonable goals in the time needed. 
Thermal Enhanced VOC Removal. Several types of thermal enhancements are available with different characteristics and applicability to different conditions. Because of the low permeability sediments in the CAMU Area, the following discussion focuses on self resistive ("Joule") heating. This technology directly "injects" AC power into the subsurface through resistance to the flow of electricity in the bulk soil/groundwater, heat is generated. Thus, the ground itself acts in a manner analogous to the heating element in a small radiant home or office heater. The geological conditions in the source area of the CAMU are suited to Joule heating so it remains a viable method. Collection of the contaminant vapors from the heated zone remains a challenge. This technology would have no effect on the $U$ and Tc-99. As a result, this approach is not recommend as a general source cleanup tool in the CAMU area.

Additional Notes: This process normally requires some moisture to be maintained in the heated zone. Since the area immediately adjacent to the electrodes heats faster than the overall treatment zone, injection of small amounts of water or electrolyte solution is often required to allow the ground to be heated to temperatures near $100^{\circ} \mathrm{C}$. A relatively successful commercial variant is called six-phase heating. Dividing the power into six phases (rather than the traditional three phases of line power) helps avoid problems because the power density near each electrode is reduced and the overall power pattern is more uniform. An advantage of six-phase heating for vadose zone contamination is that power and heat are preferentially directed into fine grained or clayey layers. These layers tend to be moister and they have been shown to be the long-term solvent reservoir in many layered geological systems such as A/M Area at Savannah River. Six phase heating was developed by the Pacific Northwest National Laboratory and has been licensed for commercial implementation. Six-phase heating is potentially applicable to similar solvent source targets as steam but with less robustness to heat below the water table and the possible need for closer borehole spacing to install electrodes. Six-phase heating is likely to be more robust than steam for low permeability conditions. Recent developments related to this technology include use of a higher power density to generate an in situ corona to stimulate in situ destruction in addition to mobilization. This particular enhancement has been observed in the laboratory and may not be suitable for initial field-testing at a large contaminated site.

Pump and Treat. This is a baseline technology that provides good performance for dissolved contaminants that can be efficiently collected using wells or trenches. Pump and treat at the CAMU; however, is limited by the continued presence of a residual source and the high degree of heterogeneity. Thus, this technology would never be recommended without source removal. Slow desorption of solvents and U from the clayey material in the source area of the CAMU and the low hydraulic conductivities (10 ${ }^{4}-10^{-7} \mathrm{~cm} / \mathrm{sec}$ ), prevent this technology from being viable, except as an interim hydraulic containment strategy.

Soil Vapor Extraction (SVE). SVE is a baseline method that has been successfully used under a wide range of source zone conditions. The biggest limitation to use of SVE for the source material associated with the CAMU is the low permeability of some of the source zone sediments and the high degree of heterogeneity. In this setting, the more 
permeable material is remediated quickly (circa years) while the less permeable material is remediated much more slowly (circa decades or centuries). Related methods, such as dual media extraction, are being performed by a large number of companies. These related technologies are based on removing as much water as possible by pumping and then cleaning up the sediment using the more efficient SVE approach (i.e., air is a more efficient VOC extraction medium than water). However, this approach would be totally ineffective on the radionuclides. The water removal can be accomplished on a local scale by using a high vacuum suction tube in the SVE well or, on a slightly larger scale, by using intensive pumping of a small number of closely spaced wells. Dual media extraction is promising for small solvent source sites in relatively permeable and homogeneous geological conditions. Specific attributes that make dual media extraction promising include: 1) residual solvent present in the capillary fringe and shallow groundwater, 2) minimal solvent source deep in aquifer zone(s) beneath the water table, and 3) avoiding implementation at sites with either very high or very low permeability. At the CAMU source, this variant would be limited by the same heterogeneity challenges as standard SVE and the ineffectiveness on the radionuclides. The treatment of the TCE in the excavated source material in a staging area could be accomplished in a manner of weeks using a simple SVE system. A similar system was designed and costed for similar mixed waste at Fernald (Fernald Technical Assistance, 2002).

Monitored Natural Attenuation. MNA is defined as the stabilization and long-term shrinking of a contaminant plume (as defined by the isoconcentration contours) by natural processes such as biodegradation or chemical reduction. In general, MNA is considered applicable to dissolved plumes only. This technology has been the subject of active research throughout the world with investment by universities, companies, and all relevant federal agencies. The Department of Defense, Environmental Protection Agency, United States Geological Survey and DOE, in particular, have invested in the study of MNA for hydrocarbon contaminants. More recently, MNA has been studied for chlorinated solvents; however, there have not been any protocols developed for metals or radionuclides. The data suggest that MNA can play a role in a long-term strategy for responsible environmental cleanup for these more challenging contaminants at appropriate sites (i.e., sites with the potential for anaerobic dehalogenation or aerobic cometabolism and perhaps even stabilization of metals and radionuclides in naturally reducing environments). Until the source term is removed at the CAMU, it is unlikely that MNA would be acceptable to either the stakeholders or the regulators and therefore is not recommended. 


\begin{tabular}{|c|c|c|c|c|c|c|}
\hline 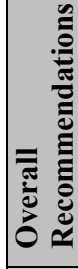 & 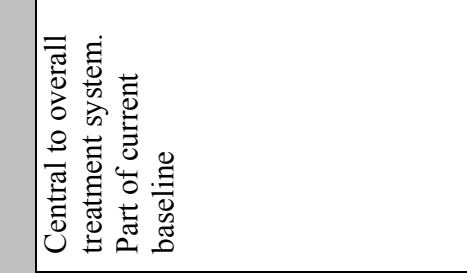 & 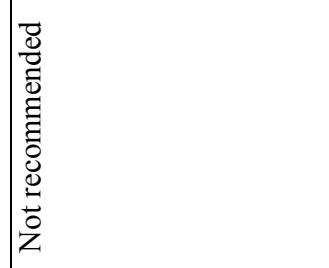 & 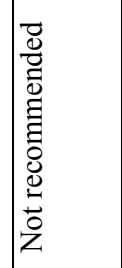 & 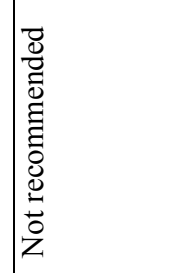 & 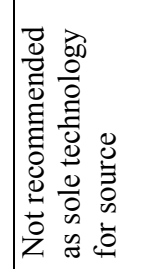 & 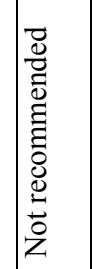 \\
\hline 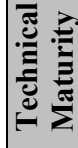 & 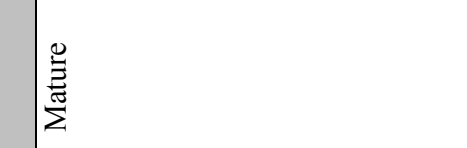 & 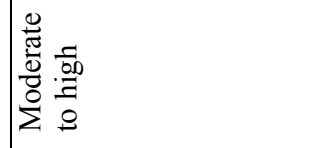 & 竞 & 孞 & 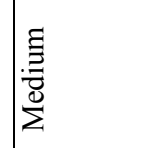 & 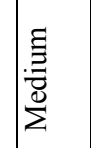 \\
\hline 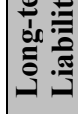 & 苛 & 品 & 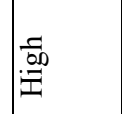 & $\mid$ & 总 & 焍 \\
\hline 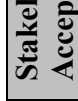 & 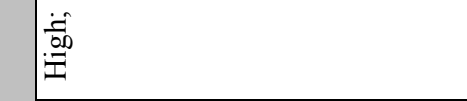 & 孞 & 䇥 & 艿 & 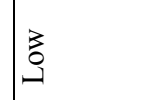 & $\mid \begin{array}{l}3 \\
0\end{array}$ \\
\hline 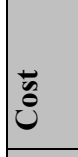 & 吕 & 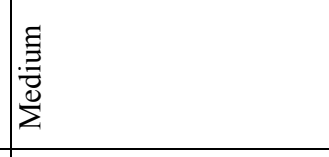 & 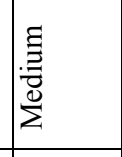 & 䒠 & 声 & : \\
\hline 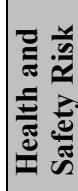 & 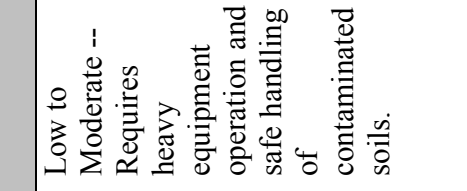 & 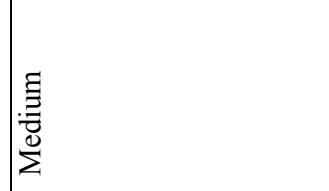 & 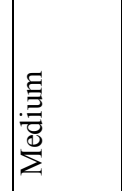 & 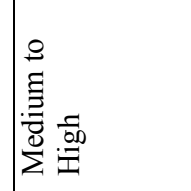 & 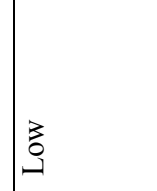 & 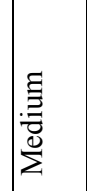 \\
\hline 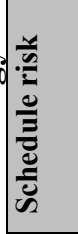 & 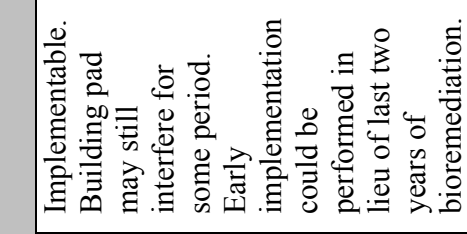 & ta & $\frac{5}{500}$ & 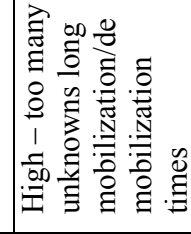 & 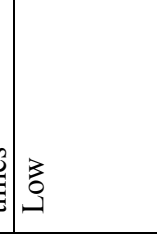 & 点 \\
\hline 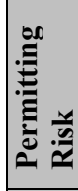 & 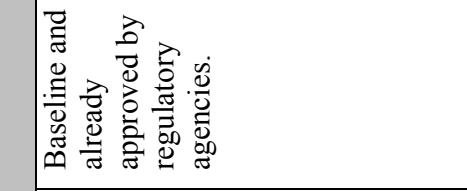 & 咅 & 馬 & 馬 & $\stackrel{.50}{.000}$ & 哥 \\
\hline 离 & 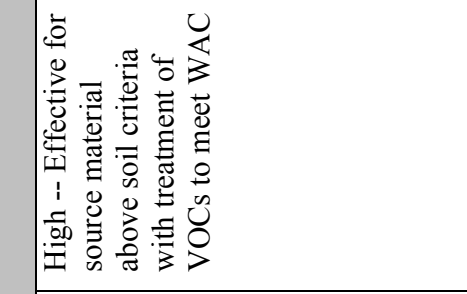 & 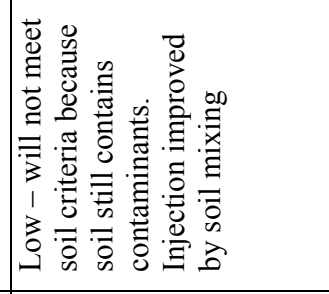 & 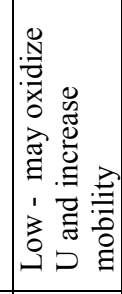 & 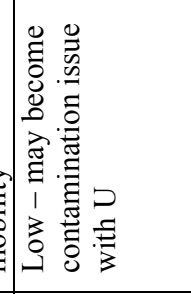 & 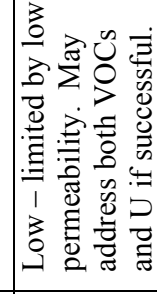 & 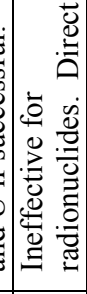 \\
\hline 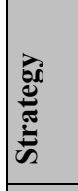 & 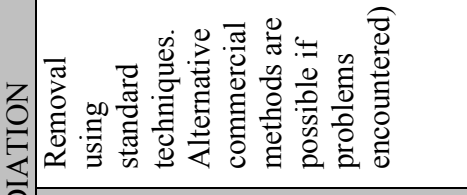 & 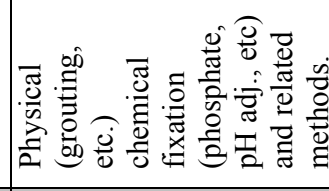 & 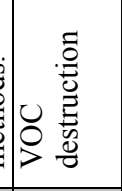 & 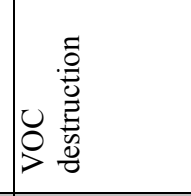 & 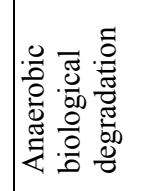 & 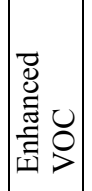 \\
\hline 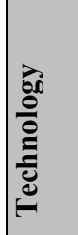 & 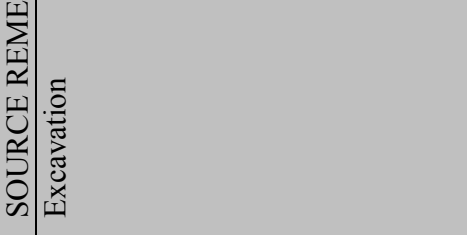 & 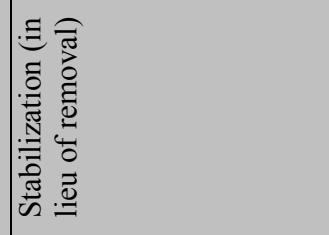 & 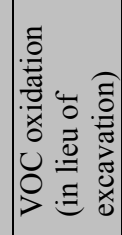 & 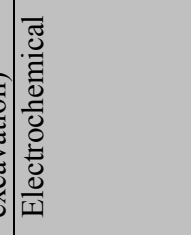 & 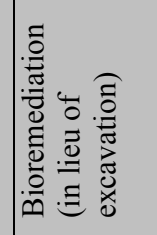 & 烍 \\
\hline
\end{tabular}




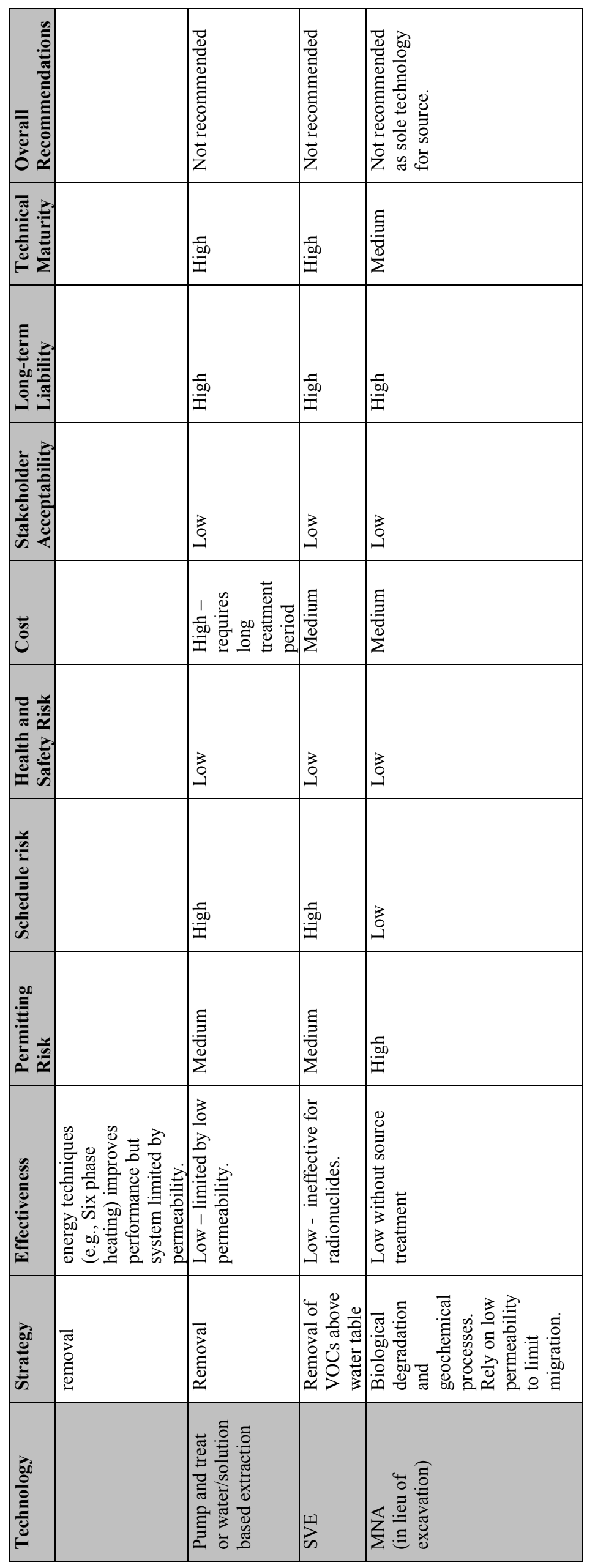

$\vec{\sim}$ 


\subsubsection{Groundwater Plume Treatment}

Bioremediation - Anaerobic. See description of source zone for a complete description of anaerobic bioremediation. Bioremediation is much more likely to be a viable solution for the dilute plume that remains after the source is removed. However, the same uncertainties and limitations will still apply, namely that the low hydraulic conductivity suggests that injection of liquid biostimulants of any type will be difficult and that incomplete dehalogenation may result in accumulation of more toxic daughter products, eg. vinyl chloride, and the bioreduction of $U$ may not be permanent or extensive enough to reduce groundwater levels to the $30 \mathrm{pCi} / \mathrm{L}$ currently required. Indeed, it is highly likely that over the long-term various groundwater wells in the area may show transient concentrations of $U$ at low levels as local reoxidation at least on a small scale is likely. In combination with source removal this technology is viable and will certainly be faster then MNA. The current injection of HRC should provide valuable information for further implementation of this strategy after the source is removed from the CAMU. A risk assessment study may make transient detection of $U$ above the MCL in groundwater less of an issue for this technology.

Bioremediation - Aerobic. Aerobic bioremediation is a well-proven technology in which aerobic microorganisms degrade chlorinated solvents by the mechanism of cometabolism. In this case, enzymatic stimulation by an added substrate under aerobic conditions results in fortuitous co-degradation of chlorinated solvents by oxidative mechanisms. Since these microorganisms do not utilize chlorinated solvents directly as a source of carbon or energy, deployment of aerobic bioremediation requires an engineering design to provide oxygen and the presence of degradable organic carbon. In some cases, contaminated soils may contain sufficient levels of degradable carbon and only oxygen addition is required. In other cases, oxygen is provided as well as degradable organic substrates delivered in solid, liquid or gaseous additions. The accumulation of unwanted degradation intermediates does not usually occur with aerobic bioremediation. Application of aerobic bioremediation for in situ treatment of contaminated soils and groundwater at Ashtabula would require that aerobic conditions be established and maintained. This would require engineering an air (or oxygen) injection system into the aquifer. This system could be a relatively simple design, such as perforated PVC piping and a low volume blower. Additionally, the bioprocess conditions would need to be held within acceptable ranges for temperature, $\mathrm{pH}$ and moisture. Macronutrient additions (primarily nitrogen and phosphorous) may also be required. The greatest drawback to aerobic bioremediation in this case is that it will not stabilize the $U$ and may in fact reoxidize $U$ that is already reduced and stable, thus increasing the solubility and mobility of the $U$ in the groundwater and soil. This technique is not as effective as anaerobic bioremediation for this site and is not recommended.

Monitored Natural Attenuation. See above for a complete description of MNA. MNA is ultimately the strategy that should be used on the dilute plume. However, MNA will not be viable unless a risk assessment is done to show that the MCL criteria used for groundwater can be safely raised to levels that are more acceptable for an industrial use site. MNA will also require a great deal of characterization, monitoring and initial verification monitoring, especially for $\mathrm{U}$ if it is to be used as a stand-alone technology after source removal. MNA 
will be more viable to the stakeholders and regulators as a follow on technology after an initial more aggressive treatment of the plume eg. bioremediation. MNA use would also be contingent on development of a more dynamic conceptual model of the site. Once the source is removed and a risk assessment done on the remaining plume a better assessment can be made as to the practicality of MNA. A phased approach on the plume of aggressive engineered in situ treatment, followed by passive treatment strategies, and then MNA should be give serious consideration.

Capping. As described for stabilization above, capping of the source area in the CAMU would minimize infiltration of surface water (from rain and snow) through the contaminated sediment at the site and slow contaminant migration into the groundwater. However, it would not stop the migration and caps normally have limited lives that would mean long-term monitoring and perhaps replacement at some time. The only viable consideration for this technique is in combination with other technologies, eg. MNA, bioremediation.

Stabilization. As discussed above for the source area, stabilization technologies can contain a plume but only temporarily and would only be viable in combination with other technologies. Stabilization of $U$ with phosphate in combination with deep soil mixing may be viable long-term solution for $U$ but will have little effect on TCE. This technology is not recommended as a standalone solution but could be a viable option if coupled with other remedies for TCE.

VOC Oxidation. As described above, chemical oxidation is an aggressive and expensive technology and more applicable to smaller source areas with more concentrated VOCs. It could have a negative effect on $\mathrm{U}$, since it would reoxidize already reduced and less soluble forms of $\mathrm{U}$. This technology is not recommended.

Thermally Enhanced VOC Removal. As discussed above for the source area. This technology would only be effective on the VOCs and would have no effect on the U. It is expensive and has a large energy requirement. It is not effective for large dilute plumes only areas with higher concentrations and more permeable soil. This technology is not recommended.

Geosiphon/Geodrain. Given the source removal area in the CAMU, the 18" storm sewer line removal and trenching adjacent to the pit left by the excavation, and the proximity of the escarpment, this technology represents a low cost and viable strategy in combination with other technologies. Because of the proximity of the escarpment, a pipe could either be drilled through the bottom of the pit at a downward angle until it exits the escarpment, or a siphon tube could be run from the bottom of the pit over the escarpment and down to an elevation below the intake of the pipe to provide a natural siphon (see figure 1). Draining the pit would cause groundwater to flow towards the pit and thus capture much of the contaminated water in the area. The water flowing from the drain or siphon could be sent to the wastewater treatment plant if necessary. After monitoring for a year a strategy involving either MNA, or a combination of bioremediation and stabilization could be used to further control the plume and eventually reach a low risk stability. Additionally, 
horizontal wells could be drilled in other directions at the time that the drain is installed to insure that the plume is not escaping the passive collection system. Further, the pit could be filled with permeable material and layered with stabilizers, reactive barriers, and biostimulants, eg. phosphate, iron, and HRC, to passively remediate and stabilize the remaining $\mathrm{U}$ and TCE. However, it should be cautioned that iron and HRC may reduce the $\mathrm{pH}, \mathrm{DO}$, and increase the BOD to undesirable levels in the drain, which could impact the wastewater treatment permit. A modification of the existing wastewater treatment permit would suffice for adding on the effluent from the drain of siphon. If permeable material is used as backfill in the source excavation then a low permeability cover should be put over this area to minimize the direct flow of surface water into this area and thereby decreasing the amount of water in the Geodrain. This strategy leverages with the source removal excavation and requires little new infrastructure or maintenance. Also by the time the drain is installed and monitored for one year, there should be enough data from the HRC injection to provide and assessment of the efficacy of additional HRC injections in the plume to more rapidly remediate the TCE and stabilize the U. Other amendments should also be considered if more rapid remediation and stabilization of the residual plume is required.

Pump and Treat. As described above for the source area this technology is unlikely to be effective at this site due to the poor permeability of the soil and the low flow rate of groundwater. Pump and treat would be a long-term investment with an unpredictable endpoint and would require a different treatment for both the U and TCE. It is not recommended.

Permeable Reactive Barrier (PRB). This technology utilizes a treatment material in a permeable trench or structure. The intercepted water is treated as it flows through the system and "clean" water is discharged. This technology has been the subject of active research throughout the world with investment by universities (Waterloo and others), companies (e.g., Environmental Technologies, Inc. and others), and all relevant federal agencies. The most common treatment material for VOCs is granular iron ("zero-valent iron"), amended granular iron, sorbents derived from industrial byproducts, or waste organic material for redox control. In the case of iron, the barrier provides an environment that dehalogenates chlorinated VOCs at they pass through because of the high energy of the surface corrosion reaction and the high surface area. The primary problems with this technology relate to the chemistry of the water exiting the barrier, which often has a high $\mathrm{pH}(>10)$ and no dissolved oxygen. Other problems include low treatment flow rate, especially in low permeability materials, sometimes expensive installation, and unknown lifetime of the barrier materials. While this technology is not a panacea for the Ashtabula groundwater plume, the site may want to consider niche uses and opportunistic uses. Specific examples include use of permeable treatment materials in some of the collection trenches that are being constructed and use of a permeable treatment system in the distal portion of the plume, eg. at the bottom of the escarpment. Distal installation would provide plume release protection in this unique setting that has a low water yield and does not justify active pumping and treatment. Distal installations would not be required if the plume is shown to be contained and not spreading and monitored natural attenuation is actively occurring. PRB will be slower than the geosiphon/geodrain and will not supply as 
good an immediate control of the plume post source removal. PRB is viable but not as effective as the Geosiphon/Geodrain. 


\begin{tabular}{|c|c|c|c|c|c|c|}
\hline 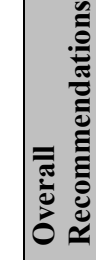 & 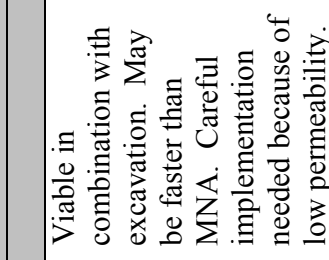 & 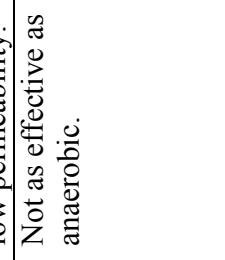 & 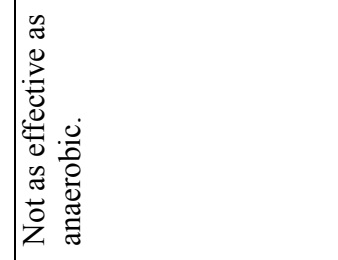 & 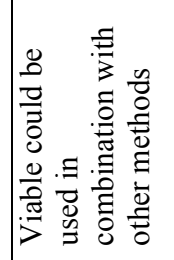 & 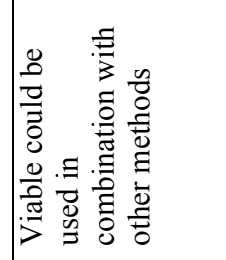 & 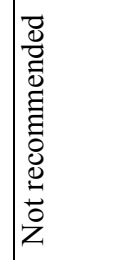 \\
\hline 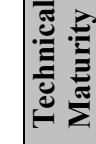 & 言 & $\mid \begin{array}{l}\text { है } \\
\frac{\bar{z}}{2}\end{array}$ & $\mid \frac{\tilde{z}}{\frac{\tilde{g}}{2}}$ & 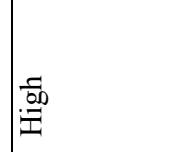 & 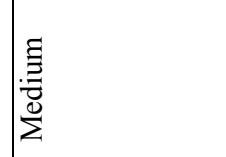 & 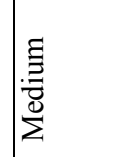 \\
\hline 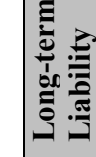 & 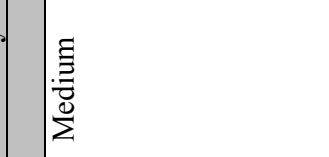 & 餢 & 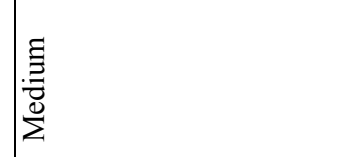 & : & 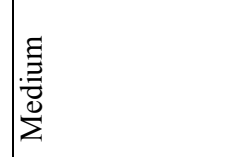 & 䒠 \\
\hline 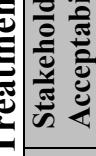 & $\frac{\Xi}{\Sigma}$ & 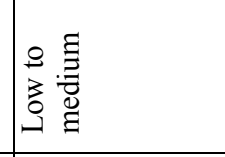 & 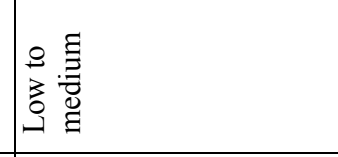 & 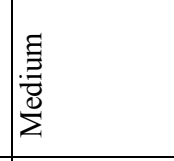 & 家 & 苟 \\
\hline $\begin{array}{l}\vec{g} \\
\text { un }\end{array}$ & 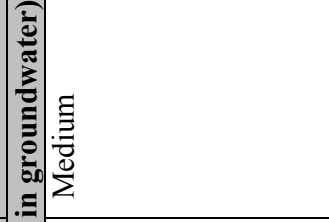 & 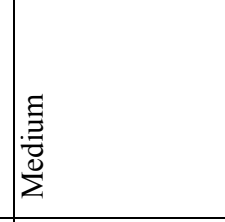 & 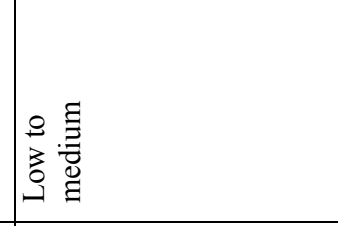 & 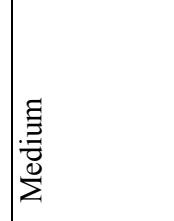 & 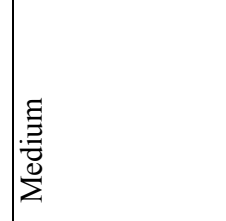 & $\frac{.}{500}$ \\
\hline 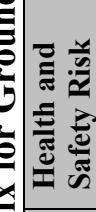 & 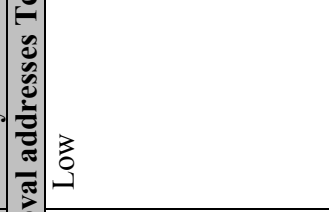 & 孞 & 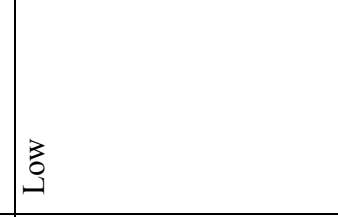 & 孞 & 童 & 声 \\
\hline 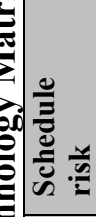 & 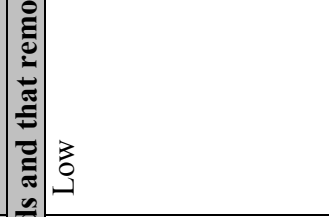 & 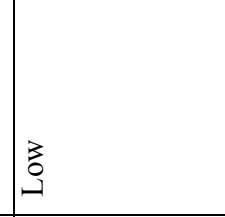 & 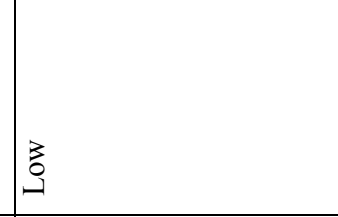 & 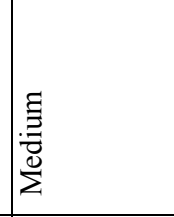 & 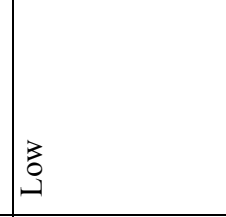 & 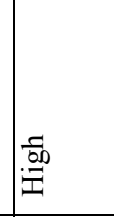 \\
\hline 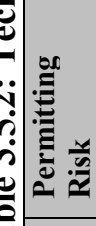 & 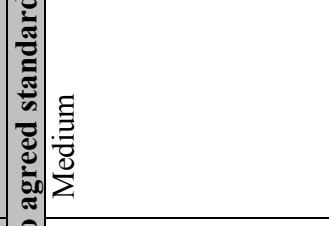 & 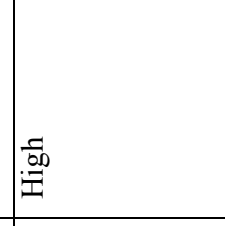 & 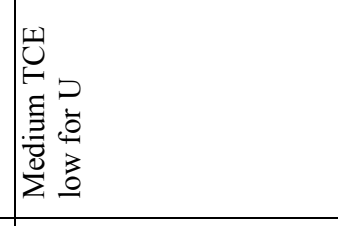 & 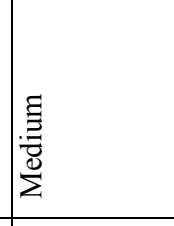 & 艿 & 总 \\
\hline 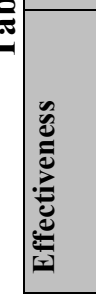 & 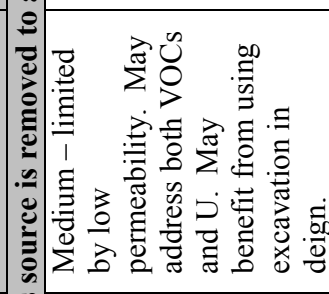 & 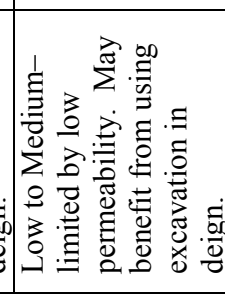 & 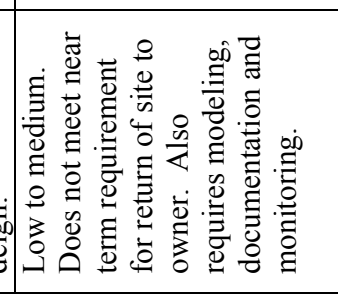 & 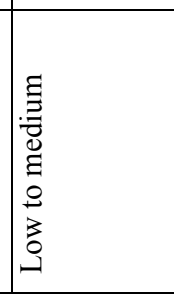 & 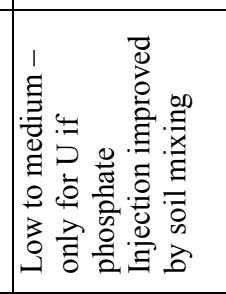 & 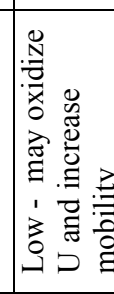 \\
\hline 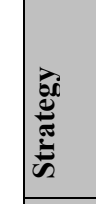 & 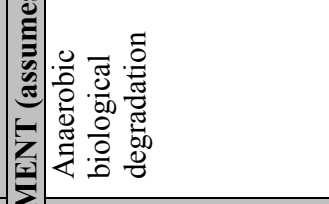 & 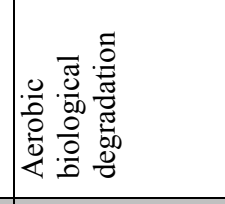 & 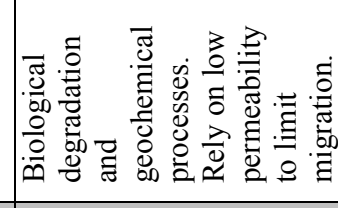 & 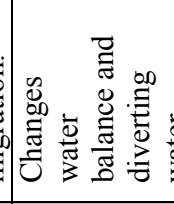 & 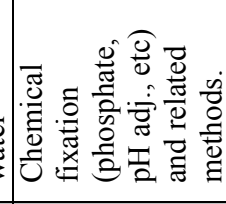 & 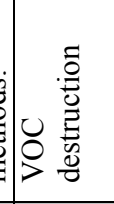 \\
\hline 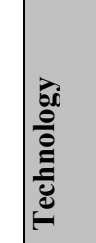 & 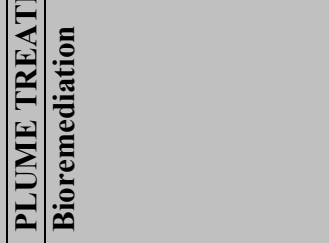 & 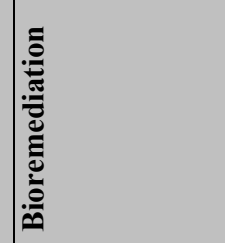 & 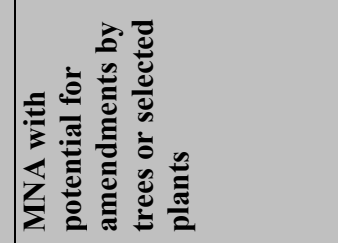 & ש̂. & 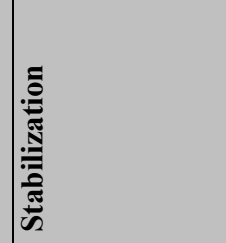 & 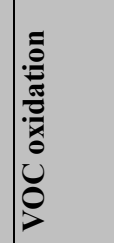 \\
\hline
\end{tabular}




\begin{tabular}{|c|c|c|c|c|}
\hline 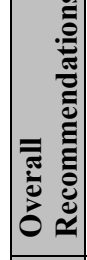 & & 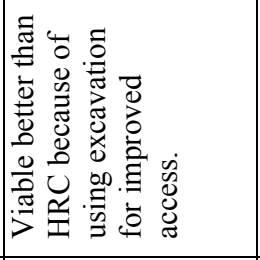 & 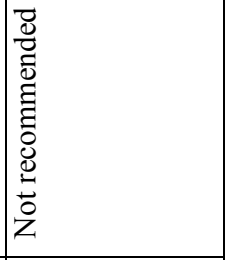 & 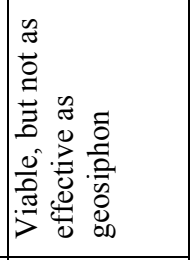 \\
\hline 㺼? & & 韮 & 竘 & 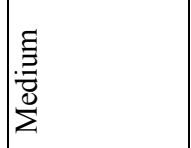 \\
\hline 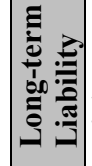 & 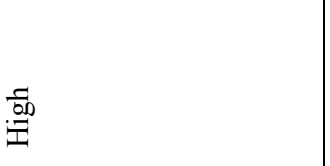 & 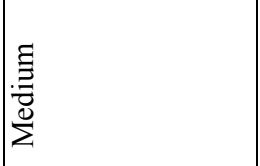 & 咅 & 声 \\
\hline 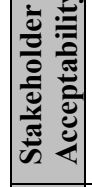 & 童 & 胥 & 孞 & 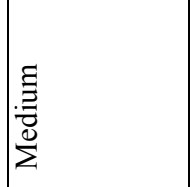 \\
\hline uे & 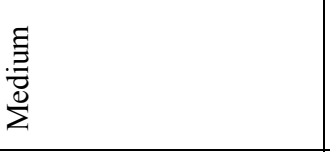 & 胥 & 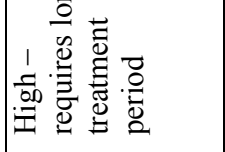 & 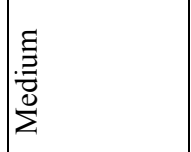 \\
\hline 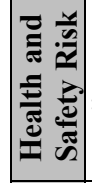 & 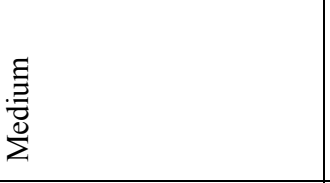 & 菏 & 孞 & 孞 \\
\hline 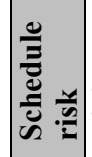 & 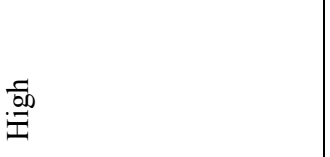 & 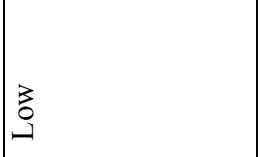 & 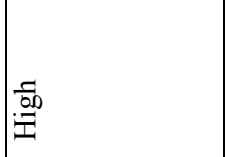 & 吕 \\
\hline 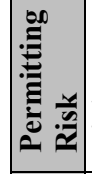 & 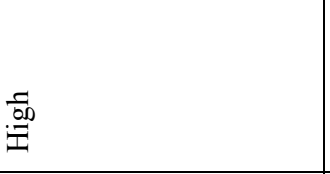 & 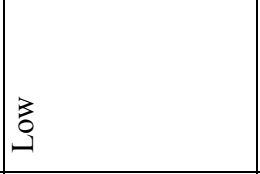 & 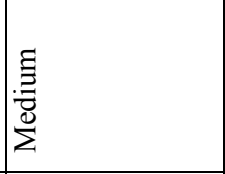 & 孞 \\
\hline 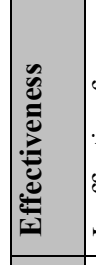 & 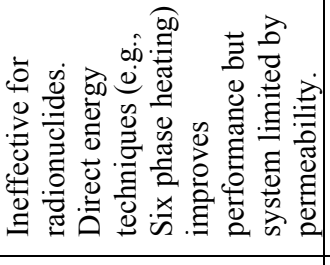 & 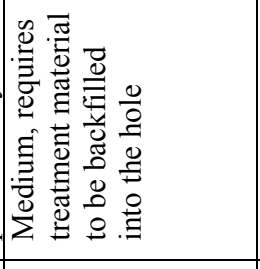 & 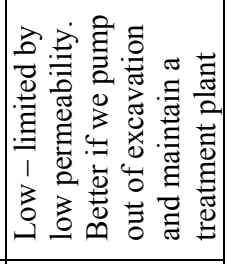 & 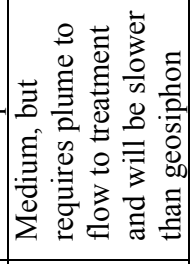 \\
\hline 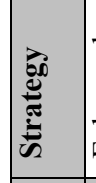 & 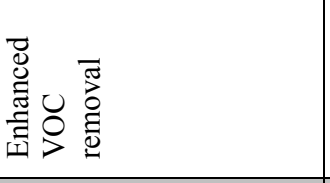 & 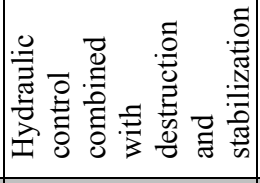 & 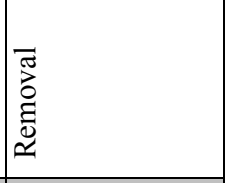 & 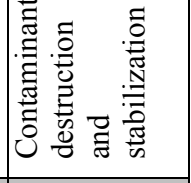 \\
\hline 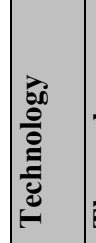 & 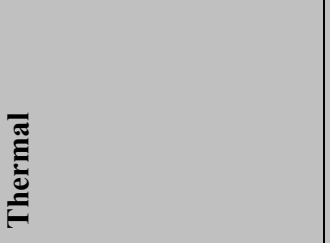 & 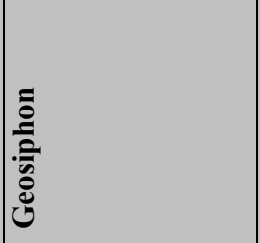 & 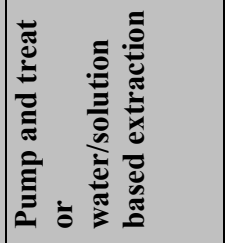 & 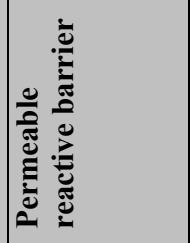 \\
\hline
\end{tabular}




\subsection{Recommendations}

To address contamination in the CAMU, the site should take steps to improve characterization of source area in CAMU, dilute plume, and higher permeability areas to develop a defensible conceptual model of the site. The SCAPS truck is coming to Ohio in late FY-02 and could be utilized to assist in this effort. Additional capability could be available under EM-50 support to readily characterize the site to better define lithology, which wells can be abandoned, where new wells may be needed, better define plume(s), enhance conceptual site model, and design monitoring strategies. The site should emphasize characterization on preferential flow paths and implementing key recommendations related to well maintenance and replacement, sentinel wells and the downgradient ponds. AEMP should also use existing infrastructure (e.g., storm sewer line removals and source excavation area for setting up a stable and sustainable system).

Steps should be taken to accelerate excavation (excavate CAMU and 18 inch storm sewer line in FY-03) and eliminate 2 years of HRC injection, expensive monitoring, and research studies. Excavation will remove Tc-99 and most of the TCE and U source terms. The TCE in the excavated material could be quickly removed while in a staging area using desorption techniques like SVE. This would allow the material to be shipped as LLRW to a storage facility like NTS (note: while this alternative is not possible for Envirocare because they would consider it mixed waste any way. NTS would not consider it mixed any longer since the TCE at Ashtabula is RCRA 'characteristic' and can be treated.) A thorough cost comparison will need to be done comparing NTS and Envirocare and the options of treating on site, and transportation costs. If building impact is still an issue, alternatives to past excavation methods should be considered that might make action possible next to building foundations, including many commercially available methods such as freeze stabilization or sequential caisson installation with permeable backfill. However, this is not believed necessary now that the building is on a more rapid remove schedule. Some damage due to subsidence under the remaining foundation may now be acceptable.

Figure 3.6. Simplified Schematic Diagrams of CAMU and Groundwater Options (a) baseline conditions, b) cross section of Geodrain, c) AEMP site configuration options)

a) 


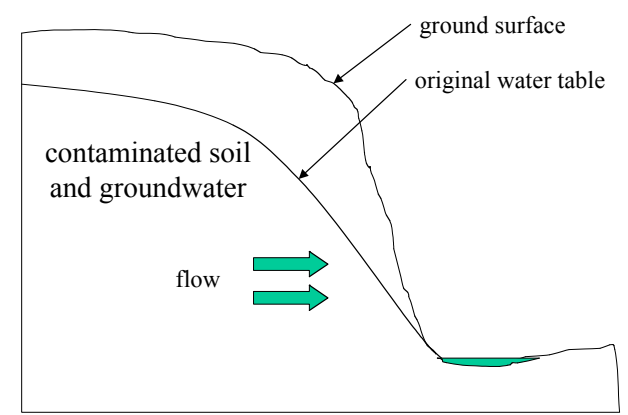

Baseline Conditions

b)

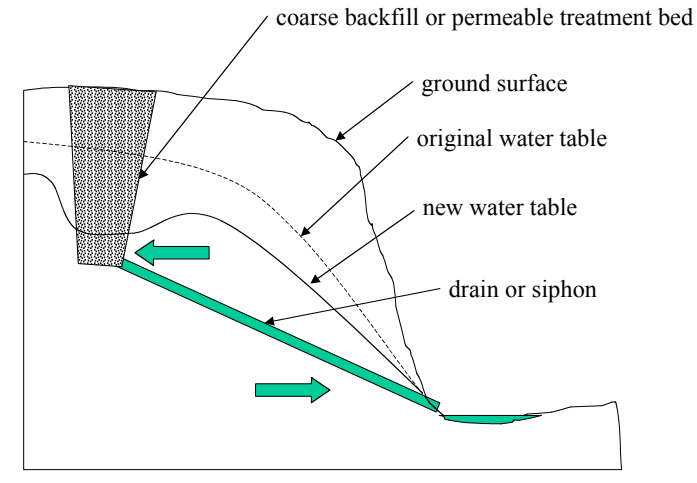

Basic GeoDrain

(see text for description of options)

c)

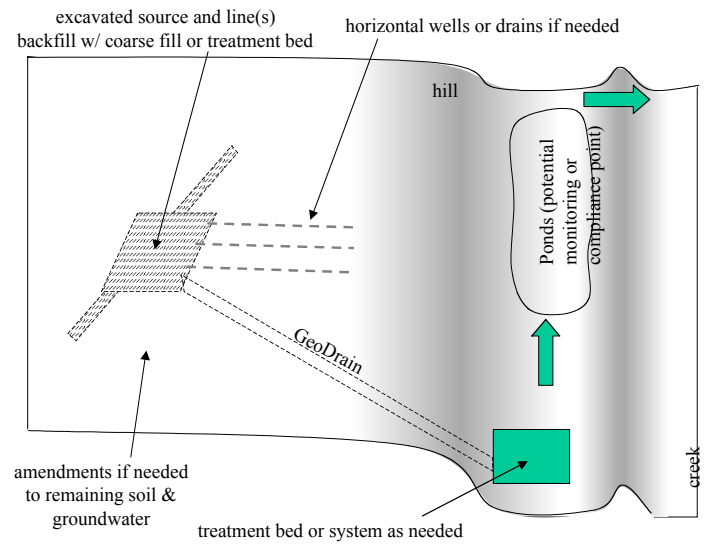

AEMP should also consider installing a high permeability backfill material to facilitate controlled drainage, possibly including amendments such as reducing agents and/or a 
phosphate source. Transitioning to monitored natural attenuation for long-term strategy should be considered. The site could also consider drilling a down gradient drain or a geosiphon (as developed and studied at Savannah River) from the bottom of the excavation. This could be supplemented as needed by lateral horizontal wells or drains. See Figure 3.6 a, b, c above for details.

If monitoring data indicates a need, AEMP should consider amendments to reduce residual on-site groundwater contamination levels to allow license termination. Then the site should transition to MNA as rapidly as possible given the constraints of a thorough risk assessment with more relevant targets for groundwater for both TCE and U.

Resolution of one of the unresolved issues: After the meeting at Ashtabula, the waste acceptance guidelines for Envirocare (Envirocare, 2001) and NTS (NTS WAC, 2002) were reviewed carefully. In addition, the WAG entities at NTS were contacted and asked about the question of treating mixed waste prior to shipping so that it could be classified and disposed of as low-level waste. Envirocare, by permit conditions with the state of Utah, cannot allow material that had ever been classified as mixed waste and treated or recertified as low level, to be disposed of in their facilities as anything but mixed waste. The NTS also appeared to be problematic, "State of Nevada regulations require that waste regulated as hazardous in the state-of-generation must be regulated as hazardous when brought into the state of Nevada therefore, such waste shall not be accepted for disposal". However, AEMP personnel verified with us that the TCE at Ashtabula has been regulatoryily classified as RCRA 'characteristic'. According to LLRW facility manager (personnel communication Pat Matthews, Bechtel NTS) 'characteristic' waste could be treated at the site and be reclassified as LLRW before shipment to NTS. (Note: The treated waste soil also needs to meet the UTS's for any defined UHC's and concentrations, from what we know now of the contaminants present, this should not be a problem). Overall, this solution has the potential to save Ashtabula large amounts in terms of acceptance by the disposal facility as LLRW instead of mixed waste. The treatment of the TCE in the excavated source material in a staging area could be accomplished in a manner of weeks using a simple SVE system. A similar system was designed and costed for similar mixed waste at Fernald (Fernald Technical Assistance, 2002).

\subsection{POTENTIAL FOR CONTINUED INVOLVEMENT}

One element in the technical assistance request was the need for the team to provide sustained support to assure that any appropriate recommendations can be successfully implemented. As personnel at AEMP review this report and select their implementation strategies, the technical assistance team will be available for general support (e.g., clarification of initial recommendations, and assistance in addressing issues or overcoming barriers encountered). Upon a request from the site, the team may provide further assistance. Examples of additional support that might be provided include the following:

In soils, the team could coordinate field screening performance evaluation and demonstrations (HPGe, RSS, FIDLER), work on closure plans for clean soils generated 
by excavation in coordination with site personnel, develop closure protocols to address partially buried contamination overlain by clean soils in coordination with site personnel, or integrate GPS/GIS with on-site Trimble (NaI).

For concrete, team members could identify data gaps that would substantiate cost/benefit analysis for concrete and propose ways to fill gaps, complete a technology assessment to determine the best tools for characterization, or work on decontamination/demolition of the concrete or closure protocols for soils beneath footers/pads if RMI decides to try to abandon in place.

For groundwater/CAMU issues, the team could provide characterization support for CAMU activities (CPT, MIP), assistance with design and optimization of Geodrain or Geosiphon, evaluate monitoring data for amendment need or selection, assist in risk assessment, provide links to $\mathrm{R} \& \mathrm{D}$ for amendment selection, design review, readiness reviews, and provide source documentation for precedence, functional design criteria etc.It is recommended that the site consider what would be most beneficial and timely and prioritize technical assistance requests. Members of the technical assistance team will continue to be available for consultation. Importantly, the assistance effort is limited to technical support - Ohio Field Office Technical Assistance is not intended as staff augmentation does not replace the need for local technical staff. The recommendations and supporting information developed by the team were developed rapidly, using a technical triage approach, and is based on a limited visit and rapid review of data and conditions. Thus, the results are recommendations to the local support staff and managers and AEMP should not be bound by the recommendations coming from the technical assistance team but rather view them as a resource. 


\section{REFERENCES}

Envirocare, 2001: Envirocare of Utah, Inc Waste Acceptance Guidelines, Revision 3, May 16, 2001, pages 25-26.

Fernald Technical Assistance, 2002: Technical Assistance to Ohio Closure Sites:

Technologies to Address Excavated VOC Contaminated Soil for Areas 3A/4A and Plant 6 at Fernald Environmental Management Project, Ohio, technical assistance \#138, WSRCTR-2002-00313.

NTS WAC, 2002: Nevada Test Site Waste Acceptance Criteria, DOE/NV-325-Rev.4, U.S. Department of Energy, National Nuclear Security Administration, Nevada

Operations Office, Waste Management Division, February 2002, pages 3-1 and 3.2. 


\section{ATTACHMENT 1}

\section{TECHNICAL ASSISTANCE BASELINE}

(E-mail to susan.meyer@srs.gov, fax to Susan Meyer at 803-725-4129, for the Lead Laboratory)

\begin{tabular}{|l|l|}
\hline Tracking & \\
Number: & \\
\hline
\end{tabular}

\begin{tabular}{|l|l|}
\hline Request Title: & $\begin{array}{l}\text { Characterization of Soil, Concrete, and Groundwater at the } \\
\text { Ashtabula Environmental Management Project }\end{array}$ \\
\hline
\end{tabular}

\begin{tabular}{|l|l|}
\hline $\begin{array}{l}\text { Contact } \\
\text { Individual: }\end{array}$ & Tom Williams, 440-993-1944 \\
\hline
\end{tabular}

\begin{tabular}{|l|l|}
\hline $\begin{array}{l}\text { Requesting } \\
\text { Organization: }\end{array}$ & DOE Ashtabula \\
\hline
\end{tabular}

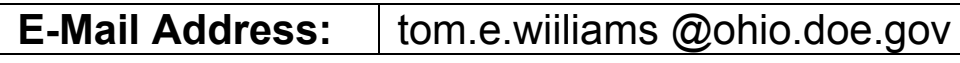

\begin{tabular}{|l|l|l|l|}
\hline Phone Number: & $440-993-1944$ & Fax Number: & $440-993-1961$ \\
\hline
\end{tabular}

\section{Scope of Work:}




\section{Task 1: Technical Assistance Team Visit to AEMP}

A technical team will visit the Ashtabula site during June. The first goal of the technical assistance visit is to develop a regulatory strategy to support remaining characterization and remediation activities dating from present to site closure under the structure of MARSSIM (Multi-Agency Radiation Survey \& Site Investigation Manual) and NUREG-5849. The strategy should focus on defining the characterization and remediation strategies to insure multi-agency regulatory approval for future activities during the overall cleanup and closure.

Second, AEMP requests technical assistance in identifying the best available technologies to address specific project needs for subsurface access and characterization of radioactive and hazardous contaminants so that these technologies can be designed into an integrated suite of technologies. This goal of this activity is to identify and specify the best approach and technologies, the equipment and supplier sources and availability, the optimum closure schedule, and the life cycle costs to achieve closure.

Specific projects now scheduled at AEMP include:

Free release of cleared areas potentially contaminated with $U$ and Tc-99. The areas include soil washing soil pads, the front parking lot area and concrete slabs remaining after $D$ and $D$ activities. The extent of contaminated soil is estimated to range from 10,000 to 70,000 tons. Innovative approaches such as the RSS or ITS should allow better delineation of the extent of contamination at the site reducing the contaminated footprint. The concrete slabs are currently in place and it is estimated that baseline removal and disposal will cost approximately $3 \mathrm{M}$. Innovative characterization approaches/technologies that can be used to characterize the contamination beneath the pads such that the pad may be left in place could potentially reduce costs.

Characterization of remaining $U$ in groundwater and sediments. Several hot spots have been identified in groundwater collected from the wells installed in the clayey sediments. Additional characterization will needed to delineate the extent of contamination.

Characterization/Cleaning of Underground Piping, Leak Detection. AEMP plans to spend significant resources to excavate all subsurface piping, sewer lines and drain line (estimated at approximately 9,000 linear feet of buried piping 2"-30" diameter. Approximately 4,000 is outside the contaminated footprint and may be subject to free release if abandoned and grouted in place if they are shown to meet site clean up criteria

Characterization of RMIDP corrective Action Management Unit (CAMU) contaminated with TCE, $U$ and Tc-99 in soils and groundwater. The baseline corrective measures for the CAMU include excavation of TCE and radionuclide contaminated soils, ex-situ vapor stripping of TCE, offsite LLW disposal of contaminated soil, pump and treat for 
groundwater remediation. Currently, the TCE is being remediated by anaerobic bioremediation by injection of HRC. Research indicates that HRC may also be effective in reducing the radionuclide contamination. Several phases of sampling for performance assessment are scheduled during the next 18 months.

Task 2: Development of a Sampling and Analysis Plan. The focus of this task will be to develop a detailed sampling and analysis plan for the activities based on the recommendations of the Technical Assistance team.

Task 3: Consulting support to Ashtabula project managers on an as needed basis to guide ongoing activities.

\section{Support:}

What resource(s) have been selected?

\section{Carol Eddy-Dilek, SRTC}

Robert Johnson, ANL

Kevin Miller, EML

What resources were offered, but not selected?

\begin{tabular}{|l|l|l|l|}
\hline $\begin{array}{l}\text { Requested Start } \\
\text { Date: }\end{array}$ & & Requested Completion Date: & \\
\hline
\end{tabular}

\section{Estimated Cost:}

Submitted By:

\section{Carol Eddy-Dilek}


ATTACHMENT 2

Contact Information for Technical Assistance Team

\begin{tabular}{|c|c|c|c|c|}
\hline Name & Organization & E-Mail & Phone & Fax \\
\hline Charoglu, Emily & EnviroIssues & echaroglu@enviroissues.com & $208-336-2505$ & $208-336-3570$ \\
\hline $\begin{array}{l}\text { Eddy-Dilek, } \\
\text { Carol }\end{array}$ & $\begin{array}{l}\text { Westinghouse } \\
\text { Savannah River } \\
\text { Company }\end{array}$ & Carol.Eddy-Dilek@ssrs.gov & $513-529-3218$ & $513-529-1542$ \\
\hline Gombert, Dirk & $\begin{array}{l}\text { Idaho National } \\
\text { Engineering } \\
\text { and } \\
\text { Environmental } \\
\text { Laboratory }\end{array}$ & DG3@inel.gov & $208-526-4624$ & \\
\hline Hazen, Terry & $\begin{array}{l}\text { Lawrence } \\
\text { Berkeley } \\
\text { National } \\
\text { Laboratory }\end{array}$ & TCHazen@,1bl.gov & $510-486-6223$ & $510-486-7152$ \\
\hline Johnson. Bob & $\begin{array}{l}\text { Argonne } \\
\text { National } \\
\text { Laboratory }\end{array}$ & rljohnson@anl.gov & $630-252-7004$ & \\
\hline Looney, Brian & $\begin{array}{l}\text { Savannah River } \\
\text { Technology } \\
\text { Center }\end{array}$ & Brian02.looney@srs.gov & $803-725-3692$ & $803-725-7673$ \\
\hline $\begin{array}{l}\text { Michael A. } \\
\text { Krstich, }\end{array}$ & EMS & mak@emswhq.com & 513.697 .6682 & 513.697 .6685 \\
\hline Rautman, Chris & $\begin{array}{l}\text { Sandia National } \\
\text { Laboratories }\end{array}$ & carautm@sandia.gov & $505-844-2109$ & $\begin{array}{l}505-250-2708 \\
\text { (cell) }\end{array}$ \\
\hline Tripp, Julia & $\begin{array}{l}\text { Idaho National } \\
\text { Engineering } \\
\text { and } \\
\text { Environmental } \\
\text { Laboratory }\end{array}$ & jtri@inel.gov & $208-526-3876$ & \\
\hline Whitmill, Larry & $\begin{array}{l}\text { Idaho National } \\
\text { Engineering } \\
\text { and } \\
\text { Environmental } \\
\text { Laboratory }\end{array}$ & WIT@inel.gov & $208-526-0357$ & $208-526-0425$ \\
\hline
\end{tabular}

